\title{
Limited Household Risk Sharing: General Equilibrium Implications for the Term Structure of Interest Rates
}

\author{
Indrajit Mitra and $\mathrm{Yu} \mathrm{Xu}$
}

\section{Working Paper 2020-20 \\ November 2020}

\begin{abstract}
We present a theory in which limited risk sharing of idiosyncratic labor income risk plays a key role in determining the dynamics of interest rates. Our production-based model relates the crosssectional distribution of labor income risk to observable aggregate labor market variables. Our model makes two key predictions. First, it predicts positive risk premia for long-term bonds while simultaneously matching key macroeconomic moments. Second, it predicts a negative correlation between current labor market conditions (as measured by labor market tightness or the job-finding rate) and future bond excess returns. We provide evidence for these predictions.
\end{abstract}

JEL classification: E24, E43, E44, G12, J64

Key words: interest rates, nondiversifiable labor income risk, labor market frictions, bond risk premia https://doi.org/10.29338/wp2020-20

The authors thank Jack Bao, George Constantinides, Andres Donangelo, Jack Favilukis, Mike Gallmeyer (discussant), Shiyang Huang, Mete Kilic (discussant), Leonid Kogan, Yang Liu, Yukun Liu (discussant), Sydney Ludvigson, Andrey Malenko, Thomas Maurer, Jianjun Miao, Francisco Palomino, Andres Schneider (discussant), Andrea Tamoni, and Haoxiang Zhu. They also thank seminar participants at the American Finance Assocation (scheduled), Academy of Financial Research Summer Institute, Atlanta Fed, BI Annual Workshop on Investment and Production-Based Asset Pricing (scheduled), City University of Hong Kong, Cornell University, European Economic Association-ESEM, European Finance Association, Federal Reserve Board, Florida State University, Labor and Finance Group, MFA, North American Summer Meeting of the Econometric Society, New York Fed, NFA, Office of Financial Research, Pennsylvania State University, Temple Univ., Texas A\&M University, University of Delaware, University of Georgia, University of Hong Kong, University of Houston, University of Maryland, University of Michigan, University of Rochester, and the Western Finance Association for helpful comments and discussions. The views expressed here are those of the authors and not necessarily those of the Federal Reserve Bank of Atlanta or the Federal Reserve System. Any remaining errors are the authors' responsibility.

Please address questions regarding content to Indrajit Mitra, Federal Reserve Bank of Atlanta, 1000 Peachtree St. NE, Atlanta, GA 30309, indrajit.mitra@atl.frb.org, or Yu Xu, Lerner College of Business and Economics, University of Delaware, yuxu@udel.edu.

Federal Reserve Bank of Atlanta working papers, including revised versions, are available on the Atlanta Fed's website at www.frbatlanta.org. Click "Publications" and then "Working Papers." To receive e-mail notifications about new papers, use frbatlanta.org/forms/subscribe. 


\section{Introduction}

Empirically, it is well-established that the risk premium of a default-free bond (over a holding period shorter than its maturity) is positive and covaries with macroeconomic conditions. However, it has been challenging to simultaneously rationalize a large, positive bond risk premium with the observed dynamics of macroeconomic variables, particularly aggregate consumption growth (Backus, Gregory, and Zin, 1989). We provide a theory which addresses this puzzle. Our model makes two predictions. First, it predicts positive risk premia for long-term bonds, while matching moments of macroeconomic variables, especially aggregate consumption growth. Second, it predicts a negative correlation between current labor market conditions (as measured by labor market tightness or the job finding rate) and future bond excess returns. ${ }^{1}$ We find support for these predictions in the data.

In our model, a representative firm hires labor supplied by a cross-section of individuals who face idiosyncratic labor income risk. The key friction that we focus on is the inability of individuals to diversify away this risk. In contrast to prior literature that takes the dynamics of labor income risk as given, income risk in our model arises as a consequence of the firm's labor policies. In particular, our production-based model relates the cross-sectional distribution of labor income risk to observable aggregate labor market variables using a labor search model.

Limited risk sharing is key for our model's first result, namely, predicting a positive risk premium for a long-term bond, while matching the dynamics of aggregate consumption growth. In our model, limited risk sharing implies an equilibrium stochastic discount factor (SDF) that is a consumption-weighted average of individual marginal utilities. Long-term

\footnotetext{
${ }^{1}$ Labor market tightness is defined as the ratio of job vacancies to the unemployment rate.
} 
bonds are a positive beta asset and earn a positive risk premium because the SDF is mean reverting. ${ }^{2}$ The mean reversion is largely driven by the dynamics of the marginal utility process of a small fraction of individuals who experience large increases in marginal utility from income loss, rather than the dynamics of aggregate consumption growth. This allows bonds to earn a positive risk premium without counterfactual implications for the dynamics of aggregate consumption growth, thereby avoiding the Backus, Gregory, and Zin (1989) puzzle. $^{3}$

The dynamics of labor income risk across individuals is endogenously determined by labor adjustment costs which we model as arising from search frictions in the labor market. The labor search setting has the advantage of allowing us to map the observed processes for labor market tightness and job-flow rates into an otherwise unobservable adjustment cost process. This disciplines our model-implied bond risk premia by restricting the process for the SDF. In our calibrated model, we find that limited risk sharing captures $40 \%$ and $55 \%$ of the average nominal and real bond risk premium, respectively, of an equal weighted portfolio of twothrough five-year bonds in the data.

The intuition for our second result, namely, a negative correlation between current labor market conditions and future bond excess returns, is as follows. Firms reduce hiring during downturns which leads to an increase in the income risk of a larger than average fraction of individuals. ${ }^{4}$ This makes the SDF more volatile, thereby raising the market price of risk in

\footnotetext{
${ }^{2}$ For a mean reverting SDF, high realizations are associated with a low expected future value. Since the latter is equal to the bond price, the bond returns are negatively correlated with the SDF. The bond therefore earns a positive risk premium.

${ }^{3}$ They point out that, in an economy with perfect risk sharing and CRRA preferences, the required mean reversion in the SDF necessary to generate realistic bond risk premia would imply a counterfactually large mean reversion in aggregate consumption growth.

${ }^{4}$ This implication of our model, namely an increase in income risk during recessions, is in line with the findings of Guvenen, Ozkan, and Song (2014). These authors find that the income of top earners in the U.S. is highly cyclical.
} 
recessions. Since a long-term bond is a positive beta asset in our model, this increases its risk premium. Since such periods are also associated with a decline in labor market tightness (due to a lower number of job vacancies and a higher unemployment rate) and the job finding rate, we obtain the negative relation between labor market conditions and bond risk premium.

We test our model's predictions using both nominal bonds and Treasury Inflation Protected Securities (TIPS). We find empirical support for our model's predictions for both types of bonds.

Literature review. Our paper contributes to two literatures and relates them. First, we contribute to the literature that analyzes the asset-pricing implications of non-diversifiable idiosyncratic labor income risk. The idea that non-diversifiable labor income risk can have a first-order effect on equities goes back to at least Constantinides and Duffie (1996) (see Schmidt 2016 and Constantinides and Ghosh 2017 for more recent examples). While labor income risk is exogenously specified in the prior literature, to the best of our knowledge, we are the first to consider the asset pricing implications of nondiversifiable labor income risk where this risk is derived from firms' labor market policies. Therefore, our theory provides an explanation for the findings of Ludvigson and Ng (2009), Joslin, Priebsch, and Singleton (2014), Huang and Shi (2016, 2019), and Bianchi, Büchner, and Tamoni (2019) that bond excess returns are predicted by principal components of macroeconomic variables, which load on labor market variables (including employment, unemployment, and vacancies, amongst others). We focus on the implications of limited risk sharing for default-free bonds; in contrast to other asset classes (e.g., equities), Treasury bonds do not require us to make additional assumptions regarding cash flow risk.

Second, we contribute to the literature on the predictability of Treasury bond returns (see 
Duffee 2013 for a review). Fama and Bliss (1987), Campbell and Shiller (1991), and Cochrane and Piazzesi (2005)), among others, document evidence for time-variation in the risk premia of nominal bonds. Pflueger and Viceira $(2011,2016)$ summarize evidence for time-variation in the risk premia of real bonds. Backus, Gregory, and Zin (1989) highlight the difficulty for a consumption-based model with perfect risk sharing and CRRA preferences to capture interest rate dynamics. This challenge has also been documented in workhorse macroeconomic models featuring production (e.g., Donaldson, Johnsen, and Mehra 1990, den Haan 1995, Rudebusch and Swanson 2008, and van Binsbergen, Fernandez-Villaverde, Koijen, and Rubio-Ramirez 2012). As a result, consumption- and production-based models that successfully capture time-varying bond risk premia use richer specifications for preferences, such as habit formation (e.g., Wachter 2006, Chen 2017, and Hsu, Li, and Palomino 2019), recursive preferences (e.g., Gallmeyer, Hollifield, Palomino, and Zin 2007, Piazzesi and Schneider 2007, Le and Singleton 2010, Rudebusch and Swanson 2012, Bansal and Shaliastovich 2013, and Kung 2015), and heterogeneity in investors' preferences (Schneider, 2019). In contrast, we rationalize timevarying bond risk premia in a production-based model with non-diversifiable labor income risk playing a key role. A related paper is Kogan, Papanikolaou, and Stoffman (2020), who obtain positive bond risk premia through a different form of imperfect risk sharing - the inability of investors to share displacement risks associated with future technological innovations.

Other approaches to rationalizing bond risk premia emphasize the supply of bonds (Greenwood and Vayanos, 2014), banks' interest rate exposure (Haddad and Sraer, 2020), disagreement and speculation regarding inflation (e.g., Hong, Sraer, and Yu 2016, and Ehling, Gallmeyer, Heyerdahl-Larsen, and Illeditsch 2018), fiscal policy (Bretscher, Hsu, and Tamoni, forthcoming), as well as using firms' marginal rate of transformation for capital to directly price bonds (Cochrane, 1988; Jermann, 2013). In addition, there is a vast literature on affine 
models of the term structure (see Singleton 2006 for a textbook treatment).

The importance of our model's source of adjustment costs, namely, search and matching frictions in the labor market has been explored by Petrosky-Nadeau, Zhang, and Kuehn (2018) for the aggregate stock market, and by Kuehn, Simutin, and Wang (2017) for the cross-section of stock returns. More generally, the importance of labor market frictions has been highlighted by Belo, Lin, and Bazdresch (2014), Donangelo (2014), Favilukis and Lin (2015), Belo, Donangelo, Lin, and Luo (2017), and Liu (2018) in the context of equity-returns, and by Favilukis, Lin, and Zhao (2019) in the context of defaultable corporate bonds.

The rest of the paper is organized as follows. Section 2 describes the model. Section 3 presents the quantitative implications of our model. Section 4 presents evidence for our model's predictions. Section 5 concludes.

\section{Model}

This section presents our general equilibrium model of real interest rates. The key determinant of the stochastic discount factor (SDF) in our model is nondiversifiable idiosyncratic labor income risk, which we relate to aggregate labor market variables through an off-the-shelf Diamond-Mortensen-Pissarides (Diamond, 1982; Mortensen and Pissarides, 1994; Pissarides, 1985) labor search model.

\subsection{The economy}

The economy is set in discrete time, with the horizon being infinite. There is a single aggregate productivity shock whose value $z_{t}$ evolves according to a first-order Markov chain with transition probabilities $p_{z z^{\prime}}=\mathbb{P}\left(z_{t+1}=z^{\prime} \mid z_{t}=z\right)$. 
2.1.1. The household. There is a single household consisting of a unit mass of ex-ante identical individuals indexed by $i \in[0,1]$. All decisions of the household are made by a single entity, which we term the "head of household," whose preferences are given by

$$
J_{t}=\mathbb{E}_{t}\left[\sum_{k=0}^{\infty} \beta^{k} \frac{\bar{C}_{t+k}^{1-\gamma}}{1-\gamma}\right],
$$

where $\beta$ is the time-preference parameter and $\gamma$ is the coefficient of relative risk aversion. The utility of the head of household is defined over the consumption index

$$
\bar{C}_{t} \equiv\left(\int_{0}^{1} C_{i t}^{1-\chi^{-1}} d i\right)^{\frac{1}{1-\chi^{-1}}}
$$

where $C_{i t}$ denotes the consumption of individual $i$ in period $t$, and $\chi$ is the head of household's elasticity of substitution across individuals' consumption.

The "head of household" is a modeling device that captures the essence of imperfect risk sharing in a heterogenous agent production-based setting, while still preserving the tractability of the representative agent framework. We further discuss this preference assumption in Section 2.3.

Idiosyncratic labor income risk. Individuals can be either employed or unemployed in each period $t$, with the $i$ th individual's employment outcome being given by

$$
e_{i t}=\left\{\begin{array}{cc}
1 & \text { with probability } N_{t} \\
0 & \text { with probability } U_{t}
\end{array}\right.
$$

To make the model tractable, we assume that, after conditioning on $N_{t}$ and $U_{t}$, the idiosyncratic employment shocks $e_{i t}$ are independent both across individuals and over time. ${ }^{5}$ As a result, the employment and unemployment probabilities, $N_{t}$ and $U_{t}$, also correspond to the

\footnotetext{
${ }^{5}$ This assumption avoids the need to track the history of cross-sectional realizations of idiosyncratic employment shocks.
} 
equilibrium aggregate employment and unemployment rates, respectively, whose dynamics are described Section 2.1.2.

While unemployment risk (3) is the sole form of idiosyncratic labor income risk in our setting, investors face additional idiosyncratic wage risk in reality. We choose to abstract from the latter as it allows us to illustrate our mechanism more cleanly. This is because our labor search setting automatically implies unemployment risk which, as we show later, is already sufficient to generate non-trivial asset pricing implications when risk sharing is limited.

Limited risk sharing. The head of household chooses each individual's consumption depending on the realization of idiosyncratic labor income shocks:

$$
C_{i t}= \begin{cases}C_{e, t} & \text { if } e_{i t}=1 \\ C_{u, t} & \text { if } e_{i t}=0\end{cases}
$$

where $C_{e, t}$ and $C_{u, t}$ denote the consumption of employed and unemployed individuals, respectively. We assume that the idiosyncratic labor income shocks (3) are non-diversifiable and subject to limited risk sharing. We capture this by restricting the consumption policies,

$$
C_{u, t} \leq \phi_{t} C_{e, t}
$$

so that the consumption of the unemployed is at most a fraction $\phi_{t} \in(0,1]$ of that of the employed. The process $\phi_{t}$ captures the degree of market incompleteness for insuring idiosyncratic labor income risk. The full risk sharing benchmark (Merz, 1995; Andolfatto, 1996), in which all individuals consume the same amount (i.e., $C_{u, t}=C_{e, t}$ ) and therefore have the same marginal utility, corresponds to the case where $\phi_{t}=1$ for all $t$. Deviations away from this benchmark are captured by letting $\phi_{t}<1$ in some states, which results in 
cross-sectional differences in marginal utilities. We further discuss equation (5) in Section 2.3.

We model risk sharing capacity to be a function of productivity,

$$
\phi_{t}=\phi\left(z_{t}\right)
$$

with $\phi(\cdot)$ being an increasing function so that risk sharing capacity is larger during good times when productivity is high.

Other than idiosyncratic labor income shocks, we assume that the head of household can trade a complete menu of state-contingent payoffs for aggregate risks. From the Fundamental Theorem of Asset Pricing (see, e.g., Dybvig and Ross 1987, 2003), the absence of arbitrage implies the existence of a SDF, $M_{t, t+n}$, which prices returns between $t$ and $t+n, R_{t, t+n}$, according to the asset pricing relationship

$$
1=\mathbb{E}_{t}\left[M_{t, t+n} R_{t, t+n}\right]
$$

We characterize the equilibrium SDF in Section 2.2.5.

2.1.2. Labor market search frictions. There is a representative firm which produces output $Y_{t}$ using a linear production technology with labor as the only input:

$$
Y_{t}=z_{t} N_{t}
$$

where $z_{t}$ is the current productivity, and $N_{t} \in[0,1]$ is the total number of individuals who are employed in that period.

The representative firm posts $V_{t}$ vacancies in period $t$ at a cost of $\kappa$ per vacancy. A total of $U_{t}=1-N_{t}$ unemployed individuals apply for these jobs. Due to search frictions, it takes time to fill vacancies. In particular, a total of $m\left(U_{t}, V_{t}\right)$ matches are successfully formed in period $t$. Following den Haan, Ramey, and Watson (2000), we parameterize the matching 
function as

$$
m\left(U_{t}, V_{t}\right)=\frac{U_{t} V_{t}}{\left(U_{t}^{\iota}+V_{t}^{\iota}\right)^{\frac{1}{\iota}}},
$$

with $\iota>0$. The contact rate between the unemployed and vacancies depends on the ratio of the number of vacancies posted to the number of job-seekers. This quantity, known as labor market tightness,

$$
\Theta_{t} \equiv V_{t} / U_{t}
$$

captures current labor market conditions. In particular, the probability of an unemployed individual successfully finding a job is

$$
f\left(\Theta_{t}\right)=m\left(U_{t}, V_{t}\right) / U_{t}=\left(1+\Theta_{t}^{-\iota}\right)^{-\frac{1}{\iota}},
$$

while the probability of the firm filling a vacancy is

$$
g\left(\Theta_{t}\right)=m\left(U_{t}, V_{t}\right) / V_{t}=\left(1+\Theta_{t}^{\iota}\right)^{-\frac{1}{\iota}} .
$$

Each period, a fraction $s$ of the employed lose their jobs and become unemployed. Employed individuals are paid wages $w_{t}$ determined using a generalized Nash-bargaining protocol, described in more detail in Section 2.2.3, in which employees obtain a fraction $\eta$ of the surplus. Unemployed individuals are paid the amount $b$ in each period of unemployment; these unemployment benefits are funded by lump sum taxes.

2.1.3. Timing of events. Figure 1 illustrates the timing of events within each period, which is as follows:

(a) At the start of period $t$, there is a mass $N_{t} \in[0,1]$ of employed individuals, and $U_{t}=1-N_{t}$ unemployed individuals. Nature draws aggregate productivity $z_{t}$ according to its law of motion. Nature also draws the idiosyncratic employment shocks $e_{i t}$. 


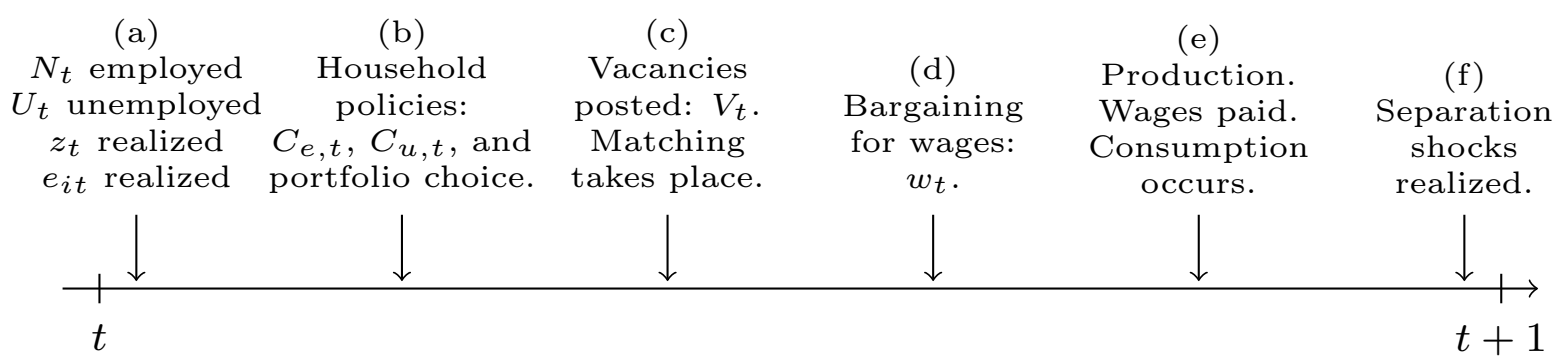

Figure 1: Timing of events within each period.

(b) The head of household chooses its policies. This includes (1) the consumption of the employed, $C_{e, t}$, and the unemployed, $C_{u, t}$, and (2) portfolio choices.

(c) The representative firm posts vacancies $V_{t}$, and labor market matching takes place. Matched individuals become employed at the start of the next period.

(d) Wages are set via a generalized Nash bargaining rule with employed individuals capturing a fraction $\eta$ of the surplus.

(e) Production takes place and output $Y_{t}$ is realized. Wages are then paid, unemployment benefits are collected, and consumption takes place.

(f) Existing matches (excluding newly formed ones) exogenously separate with probability $s$.

\subsection{Equilibrium}

2.2.1. Firm's problem. The representative firm chooses the number of vacancies to post each period to maximize the present value of dividends,

$$
F_{t}=\mathbb{E}_{t}\left[\sum_{k=0}^{\infty} M_{t, t+k} D_{t+k}\right] .
$$


The dividend in period $t$ is

$$
D_{t}=Y_{t}-w_{t} N_{t}-\kappa V_{t}
$$

where output is given by (8), $w_{t}$ is the wage paid to each employed individual and $V_{t} \geq 0$ is the number of vacancies posted by the firm. From the perspective of the firm, vacancy posting alters its labor force size through the law of motion

$$
N_{t+1}=(1-s) N_{t}+g\left(\Theta_{t}\right) V_{t}
$$

which reflects the fact that a fraction $s$ of individuals separate from existing matches each period, while a fraction $g\left(\Theta_{t}\right)$ of newly posted vacancies are matched to individuals who begin working the next period. In recursive form, the firm's problem (13) is

$$
F\left(z_{t}, N_{t}\right)=\max _{V_{t} \geq 0} D_{t}+\mathbb{E}_{t}\left[M_{t, t+1} F\left(z_{t+1}, N_{t+1}\right)\right],
$$

where future dividends are discounted using the SDF $M_{t, t+1}$, and vacancies are chosen subject to the law of motion (15) taking labor market tightness $\Theta_{t}$ as given.

The firm posts vacancies as long as the vacancy posting cost $\kappa$ is less than the marginal benefit of posting a vacancy. The latter is the product of the vacancy-filling probability $g\left(\Theta_{t}\right)$ and the marginal value of a vacancy conditional on it being filled, $\mathbb{E}_{t}\left[M_{t, t+1} \frac{\partial F\left(z_{t+1}, N_{t+1}\right)}{\partial N_{t+1}}\right]$ (an unfilled vacancy is worthless). The equilibrium amount of vacancies posted is then determined as the solution to the following complementary slackness problem:

$$
\kappa \geq g\left(\Theta_{t}\right) \mathbb{E}_{t}\left[M_{t, t+1} \frac{\partial F\left(z_{t+1}, N_{t+1}\right)}{\partial N_{t+1}}\right]
$$

with equality if and only if total vacancies $V_{t}$ are strictly positive. 
2.2.2. Household's problem. The head of household maximizes utility (1). This problem can be expressed recursively as

$$
J_{t}=\max _{C_{e, t}, C_{u, t}, \varphi_{t}^{B}, \varphi_{t}^{S}} \frac{\bar{C}_{t}^{1-\gamma}}{1-\gamma}+\beta \mathbb{E}_{t}\left[J_{t+1}\right],
$$

where the consumption index (2) is equal to

$$
\bar{C}_{t}=\left(N_{t} C_{e, t}^{1-\chi^{-1}}+U_{t} C_{u, t}^{1-\chi^{-1}}\right)^{\frac{1}{1-\chi^{-1}}}
$$

after aggregating individuals' idiosyncratic employment shocks (3). The choice variables consist of consumption for employed $\left(C_{e, t}\right)$ and unemployed $\left(C_{u, t}\right)$ individuals, and portfolio choices for the number of shares of the aggregate stock market $\left(\varphi_{t}^{S}\right)$ and single-period riskfree bonds $\left(\varphi_{t}^{B}\right)$ to hold. The aggregate stock market is a claim on the dividends of the representative firm; its cum-dividend value is given by equation (16). The choices are subject to the risk sharing constraint (5), and to the budget constraint

$$
N_{t} C_{e, t}+U_{t} C_{u, t}+\varphi_{t}^{S} P_{t}^{S}+\varphi_{t}^{B} P_{t}^{(1)} \leq w_{t} N_{t}+b U_{t}-T_{t}+\varphi_{t-1}^{S}\left(D_{t}+P_{t}^{S}\right)+\varphi_{t-1}^{B} .
$$

The left hand side of equation (20) is the sum of consumption and portfolio expenditures, with $P_{t}^{S}$ and $P_{t}^{(1)}$ denoting the ex-dividend price of the aggregate stock market and the price of the single-period risk-free bond, respectively. The right hand side consists of wage income, unemployment benefits less lump sum taxes $T_{t}$, and the payoff from portfolio choices made in the previous period. From the perspective of the head of household, the value function (18) is subject to the laws of motion

$$
N_{t+1}=(1-s) N_{t}+f\left(\Theta_{t}\right) U_{t}, \quad \text { and } \quad U_{t+1}=s N_{t}+\left(1-f\left(\Theta_{t}\right)\right) U_{t},
$$

for number of the employed and the unemployed individuals, respectively.

In equilibrium, the household owns the representative firm and single-period bonds are in 
zero net supply so that

$$
\varphi_{t}^{S}=1 \quad \text { and } \quad \varphi_{t}^{B}=0 \text { for all } t
$$

Finally, lump sum taxes are levied to exactly finance unemployment benefits,

$$
T_{t}=b U_{t} \quad \text { for all } t .
$$

2.2.3. Wages. Wages are determined by Nash bargaining. The presence of search frictions generates a positive surplus whenever individuals are matched to firms. This surplus is then split via a generalized Nash bargaining rule, with the employed individual receiving a share $\eta \in[0,1]$ of the surplus, and the representative firm receiving the remaining share $1-\eta$ of the surplus. The resulting equilibrium wage rule is given by

$$
w_{t}=\eta z_{t}+(1-\eta) b+\eta \kappa \Theta_{t} .
$$

The derivation of this result is in our Internet Appendix.

2.2.4. Equilibrium. The notion of equilibrium for the economy is standard: all agents solve their respective optimization problems and all markets clear. That is, the representative firm and head of household solve their respective value functions, (16) and (18). Wages are set according to the Nash bargaining rule (24). Labor market tightness is determined according to condition (17). The head of household owns the firm and bonds are in zero net supply (22). Furthermore, goods market clearing implies that equilibrium aggregate consumption,

$$
C_{t} \equiv \int_{0}^{1} C_{i t} d i=N_{t} C_{e, t}+U_{t} C_{u, t},
$$

is equal to

$$
C_{t}=Y_{t}-\kappa V_{t} .
$$


In equilibrium, all policies and value functions are a function of state variables $z_{t}$ and $N_{t}$. For example, $\Theta_{t}=\Theta\left(z_{t}, N_{t}\right), w_{t}=w\left(z_{t}, N_{t}\right)$, and so on.

2.2.5. Equilibrium SDF. Consider the optimality conditions for the head of household's problem (18). First, the risk sharing constraint (5) is binding in equilibrium,

$$
C_{u, t}=\phi_{t} C_{e, t}
$$

so that unemployed individuals' consumption is exactly a fraction $\phi_{t}$ of employed individuals' consumption.

Next, the inter-temporal household optimality condition implies that the SDF is equal to

$$
M_{t, t+n}=\beta^{n} \Lambda_{t+n} / \Lambda_{t}
$$

where $\Lambda_{t}$ denotes the shadow price on the budget constraint (20). We show in Appendix A.1 that, in equilibrium, the shadow price equals

$$
\Lambda_{t}=C_{t}^{-\gamma} \times \zeta_{t}
$$

The first term, $C_{t}^{-\gamma}$, is the marginal utility to the head of household from an increase in aggregate consumption $C_{t}$, which is determined from the goods market clearing condition (26). The second term is equal to

$$
\zeta_{t} \equiv\left(\int_{0}^{1} \frac{C_{i t}}{C_{t}} \times\left(\frac{C_{i t}}{C_{t}}\right)^{-\chi^{-1}} d i\right)^{\frac{1-\gamma}{1-\chi^{-1}}}
$$

It is a consumption-weighted $\left(C_{i t} / C_{t}\right)$ average of individuals' marginal utilities $\left(C_{i t}^{-\chi^{-1}}\right),{ }^{6}$ relative to the marginal utility of an individual consuming aggregate consumption $\left(C_{t}^{-\chi^{-1}}\right)$.

\footnotetext{
${ }^{6}$ This weighted average interpretation for $\zeta_{t}$ follows from writing the consumption index (2) as the certainty equivalent consumption $\bar{C}_{t}=u^{-1}\left(\int_{0}^{1} u\left(C_{i t}\right) d i\right)$, where $u\left(C_{i t}\right) \equiv C_{i t}^{1-\chi^{-1}} /\left(1-\chi^{-1}\right)$ is interpreted as the utility of an individual.
} 
From conditions (25) and (27), and noting that $U_{t}=1-N_{t}$, we see that this term is equal to

$$
\zeta_{t}=\left(N_{t}+\phi_{t}\left(1-N_{t}\right)\right)^{\gamma-1}\left(N_{t}+\phi_{t}^{1-\chi^{-1}}\left(1-N_{t}\right)\right)^{\frac{1-\gamma}{1-\chi^{-1}}}
$$

in equilibrium.

To relate the SDF (28) to that in a representative household economy with perfect risk sharing, substitute equation (29) into equation (28) to obtain

$$
M_{t, t+n}=\beta^{n}\left(\frac{C_{t+n}}{C_{t}}\right)^{-\gamma} \frac{\zeta_{t+n}}{\zeta_{t}} .
$$

The first component of the $\operatorname{SDF}(32), \beta^{n}\left(C_{t+n} / C_{t}\right)^{-\gamma}$, depends only on aggregate consumption growth and is the only term that would appear under perfect risk sharing (see, e.g., Breeden 1979). This property is illustrated by the dashed line in Figure 2: when $\phi_{t}=1$ for all $t, \zeta_{t}$ is always a constant (equal to 1 ) so that idiosyncratic labor income risk does not affect the SDF.

The second component of the $\mathrm{SDF}(32), \zeta_{t+n} / \zeta_{t}$, arises as a result of limited risk sharing (i.e., $\phi_{t}<1$ in some states). In our model, the dispersion in non-diversifiable employment outcomes across individuals becomes larger at lower levels of employment, which raises the marginal utility of the head of household. This property is illustrated by the solid line in Figure 2, which shows that $\zeta_{t}$ is a decreasing function of employment $N_{t}$ under imperfect risk sharing. Furthermore, the persistence in equilibrium employment $N_{t}$, which influences the distribution of employment shocks (3), implies that nondiversifiable labor income shocks have persistence effects on the SDF (32), which is necessary to generate non-trivial asset pricing implications. $^{7}$

\footnotetext{
${ }^{7}$ For example, Constantinides and Duffie (1996, p. 231) remark that a "[l]ack of persistence renders the pricing implications of the heterogeneous-consumer model similar to those of a homogeneous-consumer model."
} 


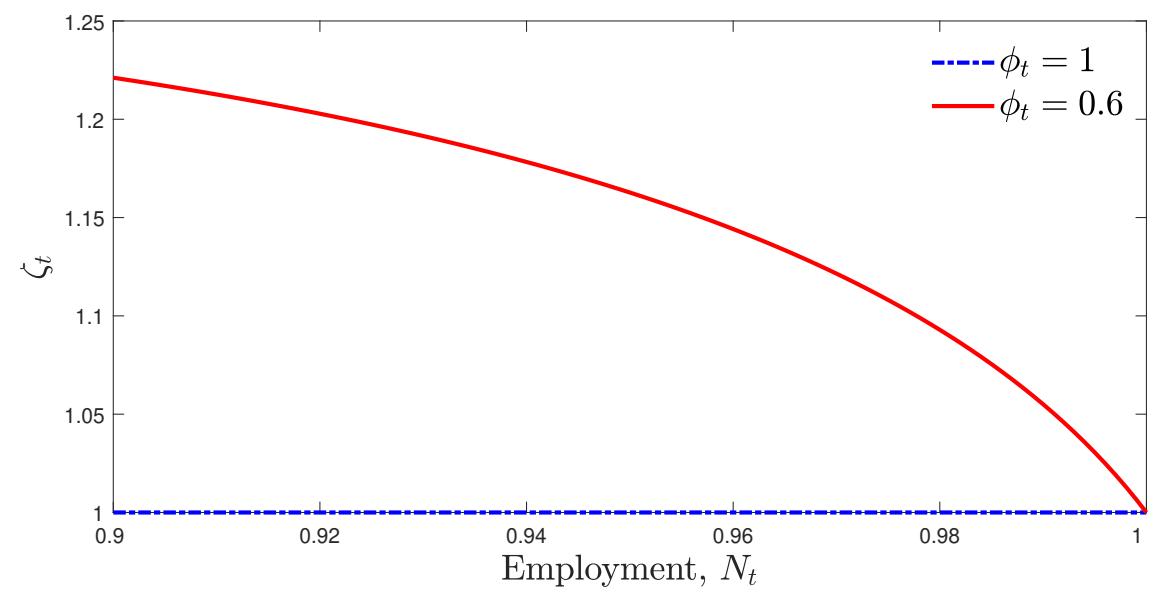

Figure 2: The function $\zeta(N)$. This figure plots the function $\zeta(N)$, defined in equation (31), with $\chi=1 / 9$ and $\gamma=2$ for various levels of employment $N$ and risk sharing capacity $\phi$.

2.2.6. Real bonds. The time $t$ price of a default-free zero coupon bond which matures in $n$ periods time and pays off a unit in real terms at maturity is given by

$$
P_{t}^{(n)}=\mathbb{E}_{t}\left[M_{t, t+n}\right]
$$

The corresponding yield to maturity is $y_{t}^{(n)}=-\frac{1}{n} \log P_{t}^{(n)}$.

Consider the investment strategy of buying a $T$-period zero coupon bond at time $t$ at a price of $P_{t}^{(T)}$, holding the bond for $H$ periods, and selling the bond for $P_{t+H}^{(T-H)}$ at time $t+H$. This investments' realized log excess holding period return (i.e., its realized log holding period return, in excess of the risk free return from buying and holding the $H$ period bond to maturity) is

$$
r x_{t+H}^{(T)} \equiv \log \left(P_{t+H}^{(T-H)} / P_{t}^{(T)}\right)-\log \left(1 / P_{t}^{(H)}\right)
$$

The corresponding ex-ante bond risk premium for this investment is

$$
h p x r_{t}^{H, T} \equiv \mathbb{E}_{t}\left[r x_{t+H}^{(T)}\right]
$$


Decomposition of real bond risk premia. To gauge the contribution of limited risk sharing to the bond risk premium (35), it is convenient to study the conditional entropy of the SDF (Backus, Chernov, and Zin, 2014), defined as

$$
L_{t}\left(M_{t, t+H}\right) \equiv \log \mathbb{E}_{t}\left[M_{t, t+H}\right]-\mathbb{E}_{t}\left[\log M_{t, t+H}\right]
$$

We can then write the risk premium (35) as

$$
h p x r_{t}^{H, T}=\mathbb{E}_{t}\left[L_{t+H}\left(M_{t+H, t+T}\right)\right]-L_{t}\left(M_{t, t+T}\right)+L_{t}\left(M_{t, t+H}\right),
$$

which we decompose into three terms:

$$
h p x r_{t}^{H, T}=h p x r_{t}^{H, T, C}+h p x r_{t}^{H, T, \zeta}+h p x r_{t}^{H, T, \text { cross }} .
$$

The first and second terms,

$$
\begin{aligned}
h p x r_{t}^{H, T, C} & \equiv \mathbb{E}_{t}\left[L_{t+H}\left(\left(C_{t+T} / C_{t+H}\right)^{-\gamma}\right)\right]-L_{t}\left(\left(C_{t+T} / C_{t}\right)^{-\gamma}\right)+L_{t}\left(\left(C_{t+H} / C_{t}\right)^{-\gamma}\right), \\
h p x r_{t}^{H, T, \zeta} & \equiv \mathbb{E}_{t}\left[L_{t+H}\left(\zeta_{t+T} / \zeta_{t+H}\right)\right]-L_{t}\left(\zeta_{t+T} / \zeta_{t}\right)+L_{t}\left(\zeta_{t+H} / \zeta_{t}\right),
\end{aligned}
$$

summarize the contribution of the aggregate consumption growth and the $\zeta_{t+n} / \zeta_{t}$ components of the SDF (32) to the bond risk premium, respectively. The third term summarizes the contribution of interaction effects between the two components of the SDF to the bond risk premium, and is defined as

$$
\begin{aligned}
\operatorname{hpxr}_{t}^{H, T, \text { cross }} \equiv & \mathbb{E}_{t}\left[C L_{t+H}\left(\left(C_{t+T} / C_{t+H}\right)^{-\gamma}, \zeta_{t+T} / \zeta_{t+H}\right)\right] \\
& -C L_{t}\left(\left(C_{t+T} / C_{t}\right)^{-\gamma}, \zeta_{t+T} / \zeta_{t}\right)+C L_{t}\left(\left(C_{t+H} / C_{t}\right)^{-\gamma}, \zeta_{t+H} / \zeta_{t}\right),
\end{aligned}
$$

where

$$
C L_{t}\left(\left(C_{t+n} / C_{t}\right)^{-\gamma}, \zeta_{t+n} / \zeta_{t}\right) \equiv L_{t}\left(\left(C_{t+n} / C_{t}\right)^{-\gamma} \zeta_{t+n} / \zeta_{t}\right)-L_{t}\left(\left(C_{t+n} / C_{t}\right)^{-\gamma}\right)-L_{t}\left(\zeta_{t+n} / \zeta_{t}\right)
$$


denotes the conditional coentropy of the two components of the SDF (Backus, Boyarchenko, and Chernov, 2018).

Appendix A.2 shows that a log-normal approximation for each of the three terms of the decomposition (38) is given by

$$
\begin{aligned}
h p x r_{t}^{H, T, C} & \approx \underbrace{\underbrace{2} \operatorname{Cov}_{t}\left(\Delta c_{t: t+H}, \Delta c_{t+H: t+T}\right)}_{\text {"Aggregate consumption persistence" }}, \\
h p x r_{t}^{H, T, \zeta} & \approx \underbrace{-\operatorname{Cov}_{t}\left(\Delta \log \zeta_{t: t+H}, \Delta \log \zeta_{t+H: t+T}\right)}_{\text {"Labor income dispersion persistence" }}, \\
\operatorname{hprr}_{t}^{H, T, \text { cross }} & \approx \underbrace{\gamma \operatorname{Cov}_{t}\left(\Delta c_{t: t+H}, \Delta \log \zeta_{t+H: t+T}\right)+\gamma \operatorname{Cov}_{t}\left(\Delta \log \zeta_{t: t+H}, \Delta c_{t+H: t+T}\right)}_{\text {"Cross-Covariance" }},
\end{aligned}
$$

where $c_{t} \equiv \log C_{t}$ denotes $\log$ aggregate consumption, and the notation $\Delta X_{t: t+k}$ denotes the difference $X_{t+k}-X_{t}$. The log-normal approximation (43) shows that the $h p x r_{t}^{H, T, C}$ and $h p x r_{t}^{H, T, \zeta}$ terms depend on the persistence of growth in aggregate consumption and labor income dispersion, respectively, while the $h p x r_{t}^{H, T, c r o s s}$ term depends on the cross-covariance between current and future growth in aggregate consumption and labor income dispersion. For this reason, we refer to $h p x r_{t}^{H, T, C}, h p x r_{t}^{H, T, \zeta}$, and $h p x r_{t}^{H, T, c r o s s}$ as the "Aggregate consumption persistence", "Labor income dispersion persistence", and "Cross-covariance" terms, respectively.

Role of non-diversifiable labor income risk. A positive risk premium for a long-term bond requires mean reversion of the SDF (see footnote 2). This holds in models with and without perfect risk sharing. However, the implications for the dynamics of aggregate consumption growth are quite different between these two models.

Under perfect risk sharing (i.e., $\phi_{t}=1$ for all $t$ ), only the "Aggregate consumption persistence" term, $h p x r_{t}^{H, T, C}$, shows up in equation (38). This leads to the bond risk premium 
puzzle highlighted by Backus, Gregory, and Zin (1989). They show that matching the observed (positive) bond risk premium would then require aggregate consumption growth to have a counterfactually large and negative autocorrelation.

Instead, when risk sharing is imperfect, labor income dispersion influences asset prices, and bond risk premia additionally depends on the terms in equation (38) involving labor income dispersion, namely, $h p x r_{t}^{H, T, \zeta}$ and $h p x r_{t}^{H, T, c r o s s}$, or the "Labor income dispersion persistence" and "Cross-covariance" terms, respectively. In our calibrated model, these additional terms account for more than $94 \%$ of the risk premium of a long-term bond in our model (see Table 4). Our model is therefore able to generate large and positive risk premia for long-term bonds without counterfactual implications for the persistence of aggregate consumption growth.

Role of labor market search frictions. The log-normal approximation (43) shows that bond risk premia crucially depend on the time-series properties of labor income dispersion risk, as summarized by the variable $\zeta_{t}$. For example, equation (43b) shows that the "Labor income dispersion persistence" term positively contributes to bond risk premia only if $\Delta \log \zeta_{t}$ displays negative autocorrelation. Since $\zeta_{t}$ is a function of $N_{t}$ in equilibrium (see equation (31)), the time series properties of $\zeta_{t}$ depends on that of the employment rate $N_{t}$ which, in turn, depends on labor adjustment costs. Rather than specify an ad hoc process for labor adjustment costs, we use an off-the-shelf labor search model which generates labor adjustment costs as an equilibrium outcome. This allows us to map the observed processes for labor market tightness and job-flow rates into an otherwise unobservable adjustment cost process (see Section 3.1 for details).

2.2.7. Nominal bonds. In this section, we introduce inflation dynamics in order to obtain nominal bond prices. This allows us to (1) test our model's predictions over a longer sample 
(US treasuries data has a substantially longer history compared to US TIPS data), and (2) avoid having to estimate a liquidity premium for TIPS, which has been found to be non-negligible (see, e.g., Pflueger and Viceira 2016).

The time $t$ price of a $n$ period default-free zero coupon bond, which pays out a unit amount in nominal terms at maturity, is given by

$$
P_{t}^{(\Phi, n)}=\mathbb{E}_{t}\left[M_{t, t+n} \exp \left(\pi_{t}-\pi_{t+n}\right)\right],
$$

where $\pi_{t}$ is the log price level at time $t$. Following Wachter (2006) and Piazzesi and Schneider (2007), we model inflation as an ARMA(1,1) process:

$$
\Delta \pi_{t+1}=\mu_{\pi}\left(1-\rho_{\pi}\right)+\rho_{\pi} \Delta \pi_{t}+\xi_{\pi} \varepsilon_{\Delta c, t+1}+\nu_{\pi} \varepsilon_{\pi, t}+\varepsilon_{\pi, t+1} .
$$

Here, $\mu_{\pi}$ is average inflation, and $\rho_{\pi}$ is the autoregressive coefficient for inflation. Innovations to inflation consists of two components. The first component is correlated with innovations to aggregate consumption growth,

$$
\varepsilon_{\Delta c, t+1} \equiv \Delta \log C_{t+1}-\mathbb{E}_{t}\left[\Delta \log C_{t+1}\right],
$$

with $\xi_{\pi}$ parameterizing the strength of this correlation. The second component is independent from the first and consists of iid shocks $\varepsilon_{\pi, t} \sim N\left(0, \sigma_{\pi}^{2}\right)$ with $\nu_{\pi}$ being the moving-average coefficient. The $\varepsilon_{\pi, t}$ shocks do not appear in the SDF (32) and are therefore not priced. Nevertheless, inflation risk is priced through its dependence on aggregate consumption growth shocks, $\varepsilon_{\Delta c, t+1}$, which are priced by the SDF.

We provide details for the computation of the nominal bond price (44) in Appendix A.3. 


\subsection{Discussion of assumptions}

We assume that the head of the household is the only decision maker in our economy and that her preferences are an aggregate of individual utilities as defined in equation (1). We discuss below how these two assumptions make our model as tractable as a representative agent model while capturing the effect of non-diversifiable idiosyncratic labor income risk on bond prices. We also discuss the simple consumption allocation rule used by the head in equation (5).

Assuming a single decision maker helps us avoid having to solve for consumption and portfolio choices of individuals in the cross-section. This is especially convenient in our production based model. Because, unlike an endowment economy where one is able to specify income processes that make the model tractable (e.g., an income process that ensures no-trade among investors as in Constantinides and Duffie 1996), the income process of individual agents in our model is endogenously determined and varies with macroeconomic conditions. By assuming a single decision maker, we avoid the need to keep track of the cross-sectional distribution of individual wealth which would otherwise have been a relevant state variable in our model.

Our assumption of the head's preference as an aggregate of individual utilities implies that non-diversifiable income risk affects the equilibrium SDF. For example, the increase in this SDF in regimes with imperfect risk sharing (i.e., $\phi_{t}<1$ ) is largely driven by the increase in marginal utility of a small fraction of individuals who experience income loss, since the head allocates lower consumption to these individuals according to equation (5). This drives up the consumption-weighted average marginal utility, and hence $\zeta_{t}$ through equation (30).

We do not derive the optimal consumption response of individuals. Instead, we assume 
a simple consumption allocation rule used by the head of household in equation (5), which directly maps individual income shocks into their consumption shocks. ${ }^{8}$ This simplifying assumption is sufficient to illustrate the asset pricing implications of limited risk sharing in our production-based setting. Together with the assumption that an individual's income risk is independent of his/her current income level, we avoid the need to track the cross-sectional distribution of individual wealth.

\section{$3 \quad$ Quantitative analysis}

In this section, we quantify and provide intuition for our model's two key predictions: (a) a yield curve that is upward sloping on average, and (b) a negative correlation between current labor market conditions (as measured by labor market tightness or the job finding rate) and future bond excess returns.

\subsection{Calibration}

We solve our model numerically using global methods (see our Internet Appendix for details). We simulate our model at monthly frequency using the parameters shown in Table 1 . We report our model-implied moments over a horizon of a quarter in Table 2, together with their data counterparts. Details for the data used in our calibration procedure are available in Appendix B.

For our baseline analysis, we model the exogenous productivity process $z_{t}$ as a two-regime

\footnotetext{
${ }^{8}$ Further endogenizing the degree of risk sharing is outside the scope of our analysis. Ai and Bhandari (2018) consider a setting in which contracting frictions endogenously determine the extent to which labor income risks can be shared.
} 
Table 1: Parameter values. We simulate our model at a monthly frequency using the parameters shown in the table below.

\begin{tabular}{lcc}
\hline Parameter & Symbol & Model \\
\hline Persistence of productivity regimes & $\lambda$ & 0.9 \\
Long-run probability, low productivity regime & $p_{1}$ & 0.167 \\
Long-run probability, high productivity regime & $p_{2}$ & 0.833 \\
Log-productivity, low productivity regime & $\log z_{1}$ & -0.022 \\
Log-productivity, high productivity regime & $\log z_{2}$ & 0 \\
Time preference parameter & $\beta$ & 0.9984 \\
Coefficient of relative risk aversion & $\gamma$ & 2 \\
Elasticity of substitution in consumption index & $\chi$ & $1 / 9$ \\
Employed individuals' bargaining power & $\eta$ & 0.025 \\
Vacancy creation cost & $\kappa$ & 0.881 \\
Curvature of matching function & $\iota$ & 1.24 \\
Job separation probability & $s$ & 0.034 \\
Unemployment benefit parameter & $b$ & 0.923 \\
Degree of risk-sharing in low productivity regime & $\left.\phi_{L} \equiv z_{1}\right)$ & 0.6 \\
Degree of risk-sharing in high productivity regime & $\phi\left(z_{2}\right)$ & 1.0 \\
Average inflation & $\mu_{\pi}$ & 0.00324 \\
Autocorrelation coefficient, inflation & $\rho_{\pi}$ & 0.81 \\
Loading on aggregate consumption growth shock, inflation & $\xi_{\pi}$ & -0.035 \\
Moving-average coefficient, inflation & $\nu_{\pi}$ & -0.338 \\
Volatility of $\varepsilon_{\pi, t}$ shocks, inflation & $\sigma_{\pi}$ & 0.00245 \\
\hline
\end{tabular}

Markov chain. ${ }^{9}$ Having a simple two-regime specification for productivity makes it easier to explain the intuition of our model, and all results presented in our main text are for this two-regime specification. We show in the Internet Appendix that our results are robust to increasing the number of states for $z_{t}$. Specifically, the Internet Appendix presents results for the case in which aggregate productivity follows a discretized $\mathrm{AR}(1)$ process with eleven productivity states. The AR(1) model produces near identical results for the yield curve and

\footnotetext{
${ }^{9}$ Note that even though there are only two regimes in our baseline specification, our model nevertheless features many states $\left(z_{t}, N_{t}\right)$ due to the presence of the endogenous state variable for employment $N_{t}$.
} 
Table 2: Moments of real variables and asset prices. This table reports model-implied moments along with its data counterparts. Yields and the equity premium are annualized; all other quantities are for a quarterly horizon. The average mean (volatility) of the yield curve is the average of the means (volatilities) of the one- through five-year nominal bonds. The data is for the period 1964Q1-2016Q4 (see Appendix B for details).

\begin{tabular}{lrr}
\hline Moment & Data & Model \\
\hline Target moments & & \\
$U:$ mean (\%) & 6.09 & 6.08 \\
$\quad$ volatility (\%) & 0.78 & 0.75 \\
$\log C$ growth: Autocorrelation & 0.32 & 0.35 \\
$\quad$ Volatility (\%) & 0.67 & 0.57 \\
Ave. nominal yield curve: mean & 5.66 & 5.61 \\
$\quad$ volatility & 3.17 & 3.37 \\
$\sigma($ Wage bill $) / \sigma($ Output) & 0.87 & 0.76 \\
& & \\
Nontarget moments & & \\
$\Theta:$ Mean & 0.58 & 0.89 \\
$\quad$ Volatility & 0.14 & 0.15 \\
Correlation $(U, \Theta)$ & -0.85 & -0.91 \\
Equity premium, annualized $(\%)$ & 6.36 & 2.61 \\
\hline
\end{tabular}

macroeconomic moments, and is additionally able to generate a higher equity premium of $4.34 \%$.

We follow Barton, David, and Fix (1962) and, without loss of generality, parameterize the transition probabilities for the two regimes to be $p_{i j}=(1-\lambda) p_{j}+\lambda$ if $i=j$, and $p_{i j}=(1-\lambda) p_{j}$ if $i \neq j$, where $p_{j}$ is the long-run probability of regime $j$, and the parameter $\lambda$ captures the persistence of aggregate regimes $(\lambda=0$ corresponds to i.i.d regimes). We choose $p_{1}=1 / 6, p_{2}=5 / 6$, and $\lambda=0.9$. These choices imply an average duration of one and five years for the low and high productivity regimes, respectively, which are in line with the durations of NBER recessions and expansions over the period 1964Q1-2016Q4. ${ }^{10}$

\footnotetext{
${ }^{10}$ Our sample stops at the end of 2016 because the updated Barnichon (2010) Help-Wanted-Index, which
} 
We normalize $\log$ productivity in the expansionary regime to $\log z_{2}=0$. We then set the difference in $\log$-productivity between the two regimes to be $\log z_{2}-\log z_{1}=0.022$ to match the unconditional volatility of the HP-filtered quarterly series for log US GDP per capita over the period 1964Q1-2016Q4 (using a smoothing parameter of 1600) which is 1.5\%.

There are five labor market parameters. We estimate the monthly job-separation probability $s$ and the curvature of the matching function $\iota$ directly from the data over the period 1964Q1 - 2016Q4. We set $s=3.4 \%$ in order to match the average monthly job-separation rate (constructed following Elsby, Michaels, and Solon 2009). We obtain a curvature of $\iota=1.24$ for the matching function (9) by minimizing the sum square error of the difference between the empirically observed job-finding rate (constructed following Elsby, Michaels, and Solon 2009) and its model counterpart. The latter is obtained by feeding the observed times-series for labor market tightness into the model's specification for the job-finding probability (11). We choose the vacancy posting cost $\kappa=0.881$ and the unemployment benefit parameter $b=0.923$ to match the first two moments of the unemployment rate. The mean unemployment rate is $6.08 \%$ in our model compared to $6.09 \%$ in the U.S. over the period 1964Q1-2016Q4. The volatility of the HP filtered series for the unemployment rate is $0.78 \%$ in the data and $0.75 \%$ in our model. Our choice of the value for $b$ is within the range of estimates of $b$ used in the literature which ranges between 0.4 used by Shimer (2005) to 0.955 used by Hagedorn and Manovskii (2008). Finally, we choose the bargaining power of employed individuals to be $\eta=0.025$ to target the ratio of the volatility of the total wage bill to the volatility of output. The value of this ratio is 0.87 in the data (Favilukis and Lin, 2015, Table 3) and 0.76 when we simulate our model.

Although not target moments, our model implied moments for labor market-tightness and we use to construct labor market tightness, stops then. 
its correlation with the unemployment rate are close to their data counterparts. Mean labor market tightness is 0.58 in the data and 0.89 in our model. The volatility of the HP filtered series for labor market tightness is 0.14 in the data and 0.15 in our model. The correlation of the unemployment rate and labor market tightness is -0.85 in the data and -0.91 in our model.

For the reasons discussed at the start of Section 2.2.7, our yield-curve-based calibration targets focus on moments of the nominal yield curve instead of the real yield curve. Our model's predictions for the nominal term structure are based on the monthly $\operatorname{ARMA}(1,1)$ inflation process described in equation (45). We obtain parameter estimates for this process using maximum likelihood estimation over the monthly sample 1964m1-2016m12. As inputs into our estimation procedure, we measure inflation using the monthly Consumption Price Index, and obtain the data counterpart to the consumption growth shocks (46) using residuals from an $\mathrm{AR}(1)$ model fitted to log aggregate consumption growth data. The resulting parameter estimates are: an average monthly inflation of $\mu_{\pi}=0.0034$, an autocorrelation coefficient of $\rho_{\pi}=0.81$, a loading on the innovation to aggregate consumption of $\zeta_{\pi}=-0.035$, a moving-average coefficient of $\nu_{\pi}=-0.338$, and a volatility of $\sigma_{\pi}=0.00245$ for the residuals $\epsilon_{\pi, t}$.

We choose the head of household's time preference parameter, $\beta=0.9984$, to target the average level of the nominal yield curve (defined as the equal-weighted average of one, two, three, four, and five year nominal yields). The average level of the nominal yield curve is $5.66 \%$ in the data and $5.61 \%$ in the model.

We choose the head of household's coefficient of relative risk aversion $\gamma=2$, the elasticity of substitution across individuals' consumption $\chi=1 / 9$, and degree of risk sharing in the low productivity regime $\phi_{L} \equiv \phi\left(z_{1}\right)=0.6$, to jointly match the average volatility of nominal yields 
(computed as the equal-weighted average of the mean volatility of the one, two, three, four, and five year nominal yields), and the autocorrelation and volatility of aggregate consumption growth. For simplicity, we fix the degree of risk sharing in the high productivity regime to be $\phi\left(z_{2}\right)=1$ so that risk sharing worsens during downturns. The average volatility of nominal yields is $3.37 \%$ in our model compared to $3.17 \%$ in the data. The autocorrelation and volatility of quarterly consumption growth in our model is 0.35 and $0.57 \%$, respectively; these values are close to their data counterparts which are $0.32 \%$ and $0.67 \%$, respectively. ${ }^{11}$

The degree of risk sharing in the low productivity regime $\phi_{L}$ is an important parameter of our model. In the Internet Appendix, we report results for a calibration with $\phi_{L}=0.8$ and where $\kappa, b$, and $\gamma$ are recalibrated so that the model-implied moments for the mean and volatility of the unemployment rate, and the average volatility of the nominal term structure once again match their respective data targets. We obtain near identical results for our model-implied yield curve and macroeconomic moments; the main effect is to lower the model-implied value for the equity premium.

In a separate exercise, we show that our results for the term structure are robust to considering an equal weighted average of individuals' utilities, $J_{t}=\mathbb{E}_{t}\left[\sum_{k=0}^{\infty} \beta^{k} \int_{0}^{1} \frac{C_{i t}^{1-\gamma}}{1-\gamma} d i\right]$, which arises as a special case of the head of household's preferences (1) in which we restrict $\chi=\gamma^{-1}$ in the CES aggregator (2). We find that, compared to our baseline model, this restricted model generates near identical results for the term structure and macroeconomic moments, but produces a lower equity premium. The details for this exercise are available in the Internet Appendix.

\footnotetext{
${ }^{11}$ Note that the seemingly large positive autocorrelation value for quarterly consumption growth in the data arises from aggregating the monthly series to a quarter (see, e.g., equation (42) of the review article Breeden, Litzenberger, and Jia 2015).
} 

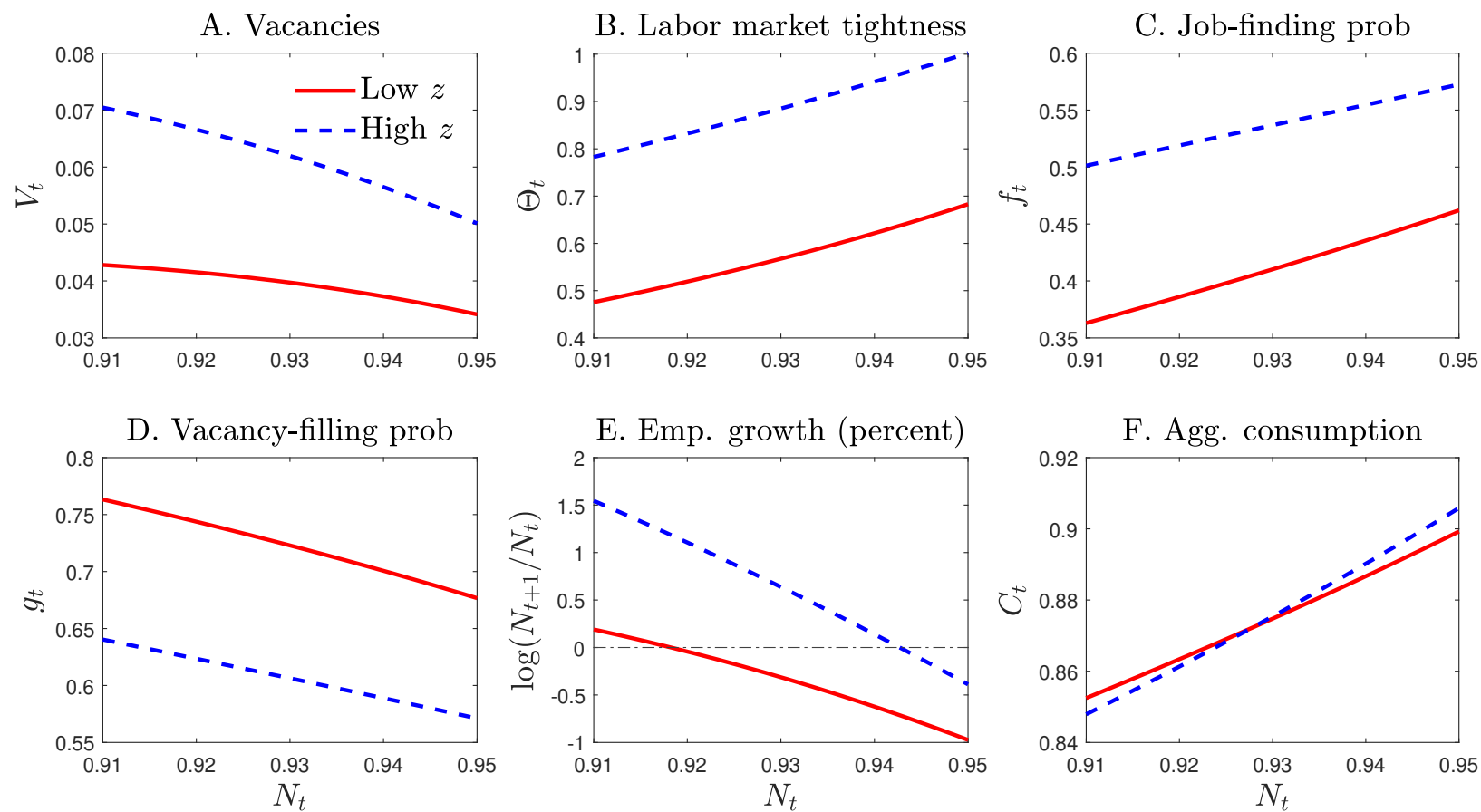

Figure 3: Hiring policies and aggregate quantities. Panels A through F plot the vacancy posting policy of the representative firm, labor market tightness, job-finding probability, vacancyfilling probability, employment growth, and aggregate consumption, respectively. The plots are for both the low (solid line) and high (dashed line) productivity regimes, and are all as a function of the current employment rate $N_{t}$.

Firm policies and real variables. In order to provide intuition for the dynamics of the equilibrium marginal utility process (29), we discuss the hiring policy of the representative firm and the resulting implications for aggregate variables.

Panel A of Figure 3 shows that firms post more vacancies in the high productivity regime compared to when productivity is low (the benefit to the firm from hiring a new individual is higher in the high productivity regime). This procyclicality in vacancy posting then leads to a procyclical labor market tightness (Panel B) which, in turn, results in a procyclical job-finding probability (Panel C) and a countercyclical vacancy-filling probability (Panel D). This is because the job-finding probability (11) and the vacancy-filling probability (12) are 
increasing and decreasing functions of labor market tightness, respectively. Panel E shows that the resulting equilibrium employment growth rate is procyclical and is positive (negative) in the high (low) productivity regime. ${ }^{12}$

The first component of the marginal utility process (29) depends on aggregate consumption. Panel F of Figure 3 shows that aggregate consumption positively depends on current employment $N$. However, the dependence of aggregate consumption on productivity is ambiguous. This is because an increase in productivity results in both a higher output as well as an increase in expenses resulting from the firm posting a larger number of vacancies (i.e., $\kappa V)$.

The second component of the marginal utility process $(29), \zeta_{t}$, behaves as follows. First, the dashed line in Figure 2 shows that $\zeta_{t}=1$ is a constant in the high productivity regime where risk sharing is assumed to be perfect $\left(\phi\left(z_{2}\right)=1\right)$. When productivity switches to the low regime, $\zeta_{t}$ increases due to a worsening of risk sharing (see the solid line in Figure 2). Furthermore, $\zeta_{t}$ becomes larger the longer the economy stays in the low productivity regime. This is because $\zeta_{t}$ is a decreasing function of the employment rate (see equation (31)), and employment growth is negative in the low productivity regime (as illustrated by the solid line in Panel E of Figure 3).

\subsection{Term structure of interest rates}

In this section, we analyze the shape of the term structure of yields. We explain how our model with imperfect risk sharing generates a yield curve that is upward sloping on average (both nominal and real) without counterfactual implications for the dynamics of aggregate

\footnotetext{
${ }^{12}$ The range of values visited by $N_{t}$ lies between 0.918 and 0.943 , which are the values for which employment growth is equal to zero in the low and high productivity regimes, respectively.
} 
Table 3: Term structure of bond yields. Bond yields are annualized and in percentage terms. Moments of nominal bond yields are estimated from the monthly, nominal zero coupon bond yields from the Fama-Bliss dataset over the period 1964m1-2016m12.

\begin{tabular}{lllrl}
\hline \multicolumn{6}{c}{ Maturity (years) } \\
1 & 2 & 3 & 4 & 5 \\
\hline
\end{tabular}

\begin{tabular}{lccccc}
\multicolumn{7}{c}{ A. Yields, mean } \\
\hline Nominal: data & 5.28 & 5.50 & 5.69 & 5.85 & 5.97 \\
Nominal: model & 5.43 & 5.58 & 5.65 & 5.68 & 5.70 \\
Real: model & 1.57 & 1.72 & 1.79 & 1.83 & 1.85 \\
& \multicolumn{7}{c}{} \\
& B. Yields, volatility & & \\
\hline Nominal: data & 3.32 & 3.26 & 3.17 & 3.09 & 3.01 \\
Nominal: model & 5.89 & 4.04 & 2.91 & 2.23 & 1.79 \\
Real: model & 5.81 & 4.01 & 2.89 & 2.21 & 1.78 \\
\hline
\end{tabular}

consumption growth.

In panel A of Table 3 we report average yields for maturities of one through five years, as observed in the data and implied by our model. The data numbers are computed from the monthly, nominal zero coupon bond yields from the Fama-Bliss dataset between the period 1964m1-2016m12. We see that our model captures the observed upward slope of the nominal term structure; the slope, as measured by the difference in yields between the five and one year bond, is $0.69 \%$ in the data and $0.27 \%$ in our model. In addition, our model implies an upward sloping term structure of the real yield curve. This is in line with the findings in Haubrich, Pennacchi, and Ritchken (2012) who estimate the difference between the five and one year real yields to be $0.51 \%$ over the period January 1982 to May $2010 .^{13,14}$

\footnotetext{
${ }^{13}$ We thank the authors of Haubrich, Pennacchi, and Ritchken (2012) for providing us with the estimates used in producing Figure 3 of their paper.

${ }^{14}$ Haubrich, Pennacchi, and Ritchken (2012) estimate the real yield curve using inflation swaps, survey data, and nominal bonds. We also obtain an upward sloping yield curve when we use TIPS data directly to
} 
In comparison, our model predicts this slope to be $0.28 \%$. Our channel, therefore, captures $40 \%$ and $55 \%$ of the observed slopes of the nominal and real term structures, respectively.

In Panel B of Table 3, we report volatilities for long-term yields for maturities one through five years, as observed in the data and as implied by our model. We see that although our model matches the average volatility of the nominal term structure (since this is a calibration target), our model-implied volatility for the one year bond is higher than that in the data (5.89\% vs. $3.32 \%)$.

Next, we use the decomposition (38) to study the contribution of limited risk sharing to our positive model-implied slope. The five minus one year unconditional real slope is related to the unconditional risk premium of an equal-weighted portfolio of two- through five-year real bonds through the identity

$$
\mathbb{E}\left[y_{t}^{(60)}-y_{t}^{(12)}\right]=\frac{1}{5} \mathbb{E}\left[h p x r_{t}^{12,24}+h p x r_{t}^{12,36}+h p x r_{t}^{12,48}+h p x r_{t}^{12,60}\right]
$$

where $h p x r_{t}^{H, T}$ is the holding period bond risk premium (35).

Table 4 reports the decomposition for the risk premium for the equal-weighted portfolio in both productivity regimes (over a holding period of a year and conditional on the mean employment level in each of the two productivity regimes). The mean conditional bond risk premium is $0.72 \%$ and $0.28 \%$ in the low and high-productivity regimes, respectively. More than $94 \%$ of the bond risk premium is due to the presence of labor income dispersion (i.e., the "Labor income dispersion persistence" (40) and the "Cross-covariance" (41) terms). Aggregate consumption risk (i.e., the "Aggregate consumption persistence" term (39)) contributes less measure the slope of the real yield curve over the period 1999m1 - 2016m12 (see the Internet Appendix for details). In fact, the slope (five minus one year yield) was positive throughout this sample period. However, the slope of the TIPS curve is much larger than the estimate in Haubrich, Pennacchi, and Ritchken (2012). This is likely because of a liquidity premium for TIPS and because of differences in the sample period-for instance, the Great Recession constitutes a non-negligible portion of the sample period $1999 \mathrm{~m} 1 — 2016 \mathrm{~m} 12$. 
Table 4: Decomposition of real bond risk premium. This table shows the contribution of each term in the decomposition (38) for an equal-weighted portfolio of two- through 5-year real bonds with a 1-year holding period, $\frac{1}{4} \mathbb{E}\left[h p x r_{t}^{12,24}+h p x r_{t}^{12,36}+h p x r_{t}^{12,48}+h p x r_{t}^{12,60}\right]$. For each of the two aggregate productivity regimes, $N$ is set to be equal its mean conditional on the regime. All numbers are in percent.

\begin{tabular}{cccc}
\hline Term & Symbol & Low productivity & High productivity \\
\hline Aggregate consumption persistence & $h p x r^{C}$ & 0.054 & 0.015 \\
Income dispersion persistence & $h p x r^{\zeta}$ & 0.404 & 0.169 \\
Cross-covariance & $h p x r^{\text {cross }}$ & 0.262 & 0.097 \\
Bond risk premium & $h p x r$ & 0.721 & 0.280 \\
\hline
\end{tabular}

than $6 \%$ of the total risk premium. Because a significant portion of the risk premium arises due to non-diversifiable idiosyncratic risk, our model provides a potential resolution of the puzzle highlighted by Backus, Gregory, and Zin (1989). In other words, our model predicts long-term bonds to have a positive and empirically realistic bond risk premium without predicting a counterfactually large negative autocorrelation of aggregate consumption growth.

Table 2 shows that the equity premium in our two-regime model is $2.61 \%$. In computing this premium, we defined equity as a levered claim on the unlevered value of the firm with a leverage-factor of 3 (Abel, 1999). ${ }^{15}$ The average stock market excess return is $6.36 \%$ over our sample period. Our model generates a higher equity premium once we increase the number of productivity states: the $\mathrm{AR}(1)$ model has an equity premium of $4.34 \%$ (see our Internet Appendix).

\subsection{Labor market conditions and bond excess returns}

Our model's second key prediction is that there is a negative correlation between current labor market conditions (as measured by labor market tightness or the job finding rate) and

\footnotetext{
${ }^{15}$ More precisely, the ex-dividend price for a levered equity claim in period $t$ is defined as $P_{t} \equiv$ $\mathbb{E}_{t}\left[M_{t, t+1}\right.$ Payof $\left.f_{t+1}\right]$, with the payoff being given by Payof $f_{t+1}=F\left(z_{t+1}, N_{t+1}\right)^{L E V}$ where $F\left(z_{t+1}, N_{t+1}\right)$ is the cum-dividend value for the unlevered firm (16) in period $t+1$, and $L E V$ is the leverage factor.
} 
Table 5: Predictive regressions in the model. This table reports the model-implied slope coefficients, $\beta^{(n)}$, from the return predictability regression (48). Panels A and B report the results when labor market tightness $\left(X_{t}=\Theta\right)$ and the job-finding rate $\left(X_{t}=f_{t}\right)$ is used as the predictive variable, respectively.

\begin{tabular}{lllll}
\hline$\overline{r x}_{t+12}$ & $r x_{t+12}^{(24)}$ & $r x_{t+12}^{(36)}$ & $r x_{t+12}^{(48)}$ & $r x_{t+12}^{(60)}$ \\
\hline
\end{tabular}

\begin{tabular}{llllll}
\multicolumn{7}{c}{ A. Labor Market Tightness } \\
\hline$\beta^{(n)}$, Data & -4.05 & -1.79 & -3.19 & -4.85 & -6.36 \\
$\beta^{(n)}$, Model & -1.05 & -0.96 & -1.07 & -1.08 & -1.09 \\
\multicolumn{6}{c}{ B. Job-finding rate } \\
\hline$\beta^{(n)}$, Data & -6.31 & -2.51 & -4.75 & -7.64 & -10.34 \\
$\beta^{(n)}$, Model & -2.69 & -2.46 & -2.75 & -2.77 & -2.77 \\
\hline
\end{tabular}

future bond excess returns. We discuss this result and its intuition next.

We run the predictive regression

$$
r x_{t+12}^{(n)}=\alpha^{(n)}+\beta^{(n)} X_{t}+\varepsilon_{t+12}^{(n)}
$$

using simulated data from our model. The left hand side variable is either the log excess return of a $n \in\{24,36,48,60\}$ month nominal bond, over a holding period of one year, or the log excess return for an equal-weighted portfolio of two through five year bonds, $\overline{r x}_{t+12} \equiv \frac{1}{4}\left(r x_{t+12}^{(24)}+r x_{t+12}^{(36)}+r x_{t+12}^{(48)}+r x_{t+12}^{(60)}\right)$. The predictive variable is either labor market tightness $\left(X_{t}=\Theta_{t}\right)$ or the job-finding rate $\left(X_{t}=f_{t}\right)$.

Table 5 reports the model-implied slope coefficient for regression (48) along with its data counterpart (taken from Section 4). Panel A shows that our model predicts lower future bond excess returns when labor market tightness is high. This is in line with the data. The magnitude of the model-implied slope coefficient on labor market tightness are about a quarter of that in the data when predicting excess returns for the equal-weighted portfolio 
(-4.05 in the data vs. -1.05 in the model). Similarly, Panel B shows that current job-finding rates negatively predict future bond excess returns both in our model and in the data, with the slope coefficient for the equal-weighted portfolio being -2.69 in our model versus -6.31 in the data.

Our model predicts a negative relationship between each of the two labor market variables and bond risk premia because the former behaves in a procyclical fashion (see Figure 3) while the latter behaves in a countercyclical fashion (see Table 4). To show why bond risk premia are countercyclical, we focus on the $\zeta_{t+n} / \zeta_{t}$ component of the SDF (32), since it is the dominant determinant of bond risk premia (see Table 4). Countercyclical bond risk premia (for a holding period of a year) results from countercyclicality in the volatility of $\zeta_{t+12} / \zeta_{t}$. Two reasons contribute to a more volatile $\zeta_{t+12} / \zeta_{t}$ when the economy is in the low productivity regime at time $t$. First, a switch to the high productivity regime over the holding period of the bond leads to a large drop in $\zeta_{t}$ from its current value to a value of 1.0 (see Figure 2). In our model, which is calibrated to NBER business cycles, the low regime lasts for one year on average so that the likelihood of such a regime change is reasonably large. Second, should the economy remain in the low productivity state, $\zeta_{t}$ will increase further due to a decline in employment. In contrast, when the economy is in the high productivity regime at time $t$, the volatility of $\zeta_{t+12} / \zeta_{t}$ is low because the high productivity regime is more persistent (with an average duration of five years) and the value of $\zeta_{t}$ remains constant (equal to one) in this regime. 


\section{Empirical evidence for bond return predictability}

Our model predicts a negative correlation between current labor market conditions and future bond excess returns. In this section, we provide evidence of our model's prediction using four variables each of which capture current labor market conditions: labor market tightness, the job-finding rate, and the job-separation rate. To the best of our knowledge, our bond predictability results for labor market tightness and the flow rates are new.

We run the predictive regression (48) using data for nominal bonds of maturities ranging between two to five years. Our sample consists of monthly observations of annual returns for the period 1964m1-2016m12 (see Appendix B for details regarding the data). Table 6 reports the summary statistics for all variables appearing in regression (48).

We begin by showing that labor market tightness negatively predicts bond excess returns, with the effect being stronger for bonds of longer maturities. Tightness determines the law of motion for (un)employment (21) and is the key variable driving labor market volatility in search models (see, e.g., Hall and Schulhofer-Wohl 2017 for recent evidence). Panel A of Table 7 reports the results for regression (48) with labor market tightness as the predictive variable (i.e., $X_{t}=\Theta_{t}$ ). We report Newey-West standard errors with twelve lags to account for the overlapping windows in the regressions. The estimated coefficients imply that a one standard deviation decrease in labor market tightness is associated with an increase of 1.05\% in excess returns for the equal weighted portfolio; the corresponding $R^{2}$ is $8.3 \%$. Across maturities, the associated increase ranges between $0.47 \%$ for the two year bond to $1.65 \%$ for the five year bond; the associated $R^{2}$ ranges between $7.3 \%$ for the two year bond and 9.3\% for the five year bond. This negative relation between labor market tightness and bond excess returns is in line with our model's predictions in Section 3.3. 
Table 6: Summary statistics. This table reports summary statistics for the monthly period 1964m12016m12. Panels A and B report summary statistics for nominal bonds' one-year holding period log excess returns and yields, respectively. All values are expressed in percentage terms. Panel C reports results for macroeconomic variables. See Appendix B for additional details regarding the data.

A. Excess returns

\begin{tabular}{crc}
\hline & Mean & SD \\
\hline$\overline{r x}$ & 0.97 & 3.64 \\
$r x^{(24)}$ & 0.48 & 1.72 \\
$r x^{(36)}$ & 0.88 & 3.15 \\
$r x^{(48)}$ & 1.21 & 4.39 \\
$r x^{(60)}$ & 1.33 & 5.43
\end{tabular}

B. Yields

\begin{tabular}{lrl}
\hline & Mean & SD \\
\hline$y_{\text {nom }}^{(12)}$ & 5.28 & 3.32 \\
$y_{\text {nom }}^{(24)}$ & 5.50 & 3.26 \\
$y_{\text {nom }}^{(36)}$ & 5.69 & 3.17 \\
$y_{\text {nom }}^{(48)}$ & 5.85 & 3.09 \\
$y_{\text {nom }}^{(60)}$ & 5.97 & 3.01
\end{tabular}

C. Macroeconomic moments

\begin{tabular}{|c|c|c|c|c|c|}
\hline & Mean & $\mathrm{SD}$ & & Mean & $\mathrm{SD}$ \\
\hline$\Theta$ & 0.59 & 0.26 & $F F R$ & 5.35 & 3.75 \\
\hline$f$, monthly & 0.55 & 0.15 & $I N F$, monthly & 0.32 & 0.32 \\
\hline$s$, monthly & 0.034 & 0.006 & $M W D G D P$ & 2.28 & 1.11 \\
\hline
\end{tabular}

Notes. The reported values for standard deviations are not HP-filtered, and are therefore different from their HP-filtered counterparts in Table 2.

Next, we report bond excess return predictability results for the job-finding rate $f_{t}$ and the job-separation rate $s_{t}$, separately. We construct the two job flow rates following Elsby, Michaels, and Solon (2009). Panel B of Table 7 shows that the job-finding rate negatively forecasts bond excess returns, with the regression coefficients increasing in magnitude as a function of the maturity of the bond. This is again in line with our model's prediction from Section 3.3. Panel C of Table 7 shows that, in contrast to the job-finding rate, the job separation rate does not forecast bond returns - the estimated slopes for the job separation rate are all insignificant. Our modeling assumption of a constant job separation rate reflects this finding. 
Table 7: Labor market variables and real bond excess returns. Panels A through C report results for the univariate return predictability regression (48) for nominal bonds with labor market tightness, the job-finding rate, and the job separation rate being the predictive variable, respectively. Observations are for annual returns at a monthly frequency over the period 1964m1-2016m12 (all regressions have 636 observations). Parenthesis enclose Newey-West t-statistics computed with 12 lags.

\begin{tabular}{|c|c|c|c|c|c|}
\hline & $\overline{r x}_{t+12}$ & $r x_{t+12}^{(24)}$ & $r x_{t+12}^{(36)}$ & $r x_{t+12}^{(48)}$ & $r x_{t+12}^{(60)}$ \\
\hline & \multicolumn{5}{|c|}{ A. Results for $X_{t}=\Theta_{t}$} \\
\hline$\beta_{\Theta}^{(n)}$ & $\begin{array}{l}-4.05^{* * *} \\
(-3.33)\end{array}$ & $\begin{array}{c}-1.79^{* *} \\
(-2.97)\end{array}$ & $\begin{array}{c}-3.19^{* *} \\
(-2.95)\end{array}$ & $\begin{array}{l}-4.85^{* * *} \\
(-3.32)\end{array}$ & $\begin{array}{l}-6.36^{* * *} \\
(-3.60)\end{array}$ \\
\hline$\alpha_{\Theta}^{(n)}$ & $\begin{array}{c}3.32^{* * *} \\
(4.05)\end{array}$ & $\begin{array}{l}1.51^{\text {*** }} \\
(3.82)\end{array}$ & $\begin{array}{l}2.73^{* * *} \\
(3.79)\end{array}$ & $\begin{array}{c}4.02^{* * *} \\
(4.05)\end{array}$ & $\begin{array}{c}5.02^{* * *} \\
(4.15)\end{array}$ \\
\hline \multirow[t]{2}{*}{$R^{2}$} & .083 & .073 & .069 & .082 & .093 \\
\hline & \multicolumn{5}{|c|}{ B. Results for $X_{t}=f_{t}$} \\
\hline$\beta_{f}^{(n)}$ & $\begin{array}{l}-6.31^{* *} \\
(-3.19)\end{array}$ & $\begin{array}{c}-2.51^{*} \\
(-2.50)\end{array}$ & $\begin{array}{l}-4.75^{* *} \\
(-2.72)\end{array}$ & $\begin{array}{c}-7.64^{* *} \\
(-3.22)\end{array}$ & $\begin{array}{c}-10.34^{* * *} \\
(-3.53)\end{array}$ \\
\hline$\alpha_{f}^{(n)}$ & $\begin{array}{l}4.46^{* * *} \\
(3.98)\end{array}$ & $\begin{array}{l}1.86^{* * *} \\
(3.35)\end{array}$ & $\begin{array}{l}3.50^{* * *} \\
(3.59)\end{array}$ & $\begin{array}{l}5.43^{* * *} \\
(4.02)\end{array}$ & $\begin{array}{c}7.04^{* * *} \\
(4.19)\end{array}$ \\
\hline \multirow[t]{2}{*}{$R^{2}$} & .063 & .045 & .048 & .063 & .076 \\
\hline & \multicolumn{5}{|c|}{ C. Results for $X_{t}=s_{t}$} \\
\hline$\beta_{s}^{(n)}$ & $\begin{array}{l}-27.92 \\
(-0.36)\end{array}$ & $\begin{array}{l}11.48 \\
(0.32)\end{array}$ & $\begin{array}{l}-14.77 \\
(-0.22)\end{array}$ & $\begin{array}{l}-40.18 \\
(-0.43)\end{array}$ & $\begin{array}{l}-68.20 \\
(-0.59)\end{array}$ \\
\hline$\alpha_{s}^{(n)}$ & $\begin{array}{c}1.92 \\
(0.79)\end{array}$ & $\begin{array}{c}0.09 \\
(0.08)\end{array}$ & $\begin{array}{c}1.38 \\
(0.66)\end{array}$ & $\begin{array}{c}2.57 \\
(0.88)\end{array}$ & $\begin{array}{c}3.65 \\
(1.01)\end{array}$ \\
\hline$R^{2}$ & .002 & .002 & .001 & .003 & .006 \\
\hline
\end{tabular}

More broadly, Ludvigson and Ng (2009), Joslin, Priebsch, and Singleton (2014), Huang and Shi (2016, 2019), and Bianchi, Büchner, and Tamoni (2019) show a robust link between bond excess returns and principal components of a wide set of real macroeconomic variables, 
which include labor market variables such as employment, unemployment, and vacancies, amongst others. In particular, Ludvigson and Ng (2009) find bond excess returns to be predicted by a principal component of real macroeconomic variables that has a large loading on employment and hours. Our theory provides an explanation for these findings.

We conclude our empirical analysis with robustness results in which we show that our results above remain unchanged even after we control for forces that we did not explicitly model. These include monetary policy and changes in the supply of outstanding government bonds. As a further robustness check, we also control for the level of inflation. For nominal bonds, we rerun regression (48) with additional controls for monetary policy (measured by the federal funds rate), inflation (measured using the CPI index), and bond supply (measured by the maturity-weighted debt to GDP series from Greenwood and Vayanos 2014). These results are shown in Table B.1 in Appendix B. Our findings remain unchanged: labor market tightness and the job-finding rate continue to negatively forecast excess returns, while the job-separation rate remains insignificant.

For real bonds, we rerun the univariate regression (48) using data on Treasury InflationProtected Securities (TIPS) as the left hand side variable over the sample period 1999m12016m12. Our findings remain unchanged from those without these additional controls. These results are available in our Internet Appendix.

\section{Conclusion}

We present a theory in which limited risk sharing of idiosyncratic labor income risk across individuals plays a key role in determining the dynamics of interest rates. In the general equilibrium, the income risk faced by individuals arises as a consequence of labor policies 
of the firm. In our model, labor search frictions endogenously generate labor adjustment costs that play an important role in shaping the dynamics of the distribution of idiosyncratic income risk; this approach has the advantage of allowing us to map an unobserved adjustment cost process to observable labor market variables.

Our model makes two predictions, both of which are supported by the data. First, it predicts positive risk premia for long-term bonds, while matching moments of macroeconomic variables, especially aggregate consumption growth. As a result of limited risk sharing, the dynamics of the SDF is mainly driven by the marginal utility process of a small fraction of individuals who experience large increases in marginal utility from income loss. This allows bonds to earn a positive risk premium without counterfactual implications for the dynamics of aggregate consumption growth, thereby avoiding the Backus, Gregory, and Zin (1989) puzzle.

Second, consistent with the data, our model predicts a negative correlation between current labor market conditions (as measured by labor market tightness or the job finding rate) and future bond excess returns. This predictability in bond excess returns arises in our model because the SDF is more volatile during periods of deterioration in labor market conditions. 


\section{Appendix}

\section{A Model Appendix}

\section{A.1 Derivation of the SDF}

The Lagrangian for the head of household's maximization problem (18) is given by

$$
\begin{aligned}
\mathscr{L}_{t}= & \frac{\left(N_{t} C_{e, t}^{1-\chi^{-1}}+U_{t} C_{u, t}^{1-\chi^{-1}}\right)^{\frac{1-\gamma}{1-\chi^{-1}}}}{1-\gamma}+\mathbb{E}_{t}\left[J_{t+1}\right]+\Psi_{t}\left(\phi_{t} C_{e, t}-C_{u, t}\right) \\
& +\Lambda_{t}\left[w_{t} N_{t}+b U_{t}-T_{t}+\varphi_{t-1}^{S}\left(D_{t}+P_{t}^{S}\right)+\varphi_{t-1}^{B}-N_{t} C_{e, t}-U_{t} C_{u, t}-\varphi_{t}^{S} P_{t}^{S}-\varphi_{t}^{B} P_{t}^{(1)}\right]
\end{aligned}
$$

where $\Psi_{t}$ and $\Lambda_{t}$ are the multipliers on the risk sharing constraint (5) and the budget constraint (20), respectively, and the laws of motion (21) are implicitly assumed by the conditional expectation appearing in equation (A.1).

The characterization of the SDF in equation (28) can be obtained by combining the first order conditions characterizing optimal portfolio choice,

$$
\Lambda_{t} P_{t}^{S}=\mathbb{E}_{t}\left[\frac{\partial J_{t+1}}{\partial \varphi_{t}^{S}}\right], \quad \text { and } \quad \Lambda_{t} P_{t}^{(1)}=\mathbb{E}_{t}\left[\frac{\partial J_{t+1}}{\partial \varphi_{t}^{B}}\right]
$$

with the envelope conditions

$$
\frac{\partial J_{t+1}}{\partial \varphi_{t}^{S}}=\Lambda_{t+1}\left(D_{t+1}+P_{t+1}^{S}\right), \quad \text { and } \quad \frac{\partial J_{t+1}}{\partial \varphi_{t}^{B}}=\Lambda_{t+1}
$$

To obtain equation (29) for the shadow price $\Lambda_{t}$, begin with the first order conditions for consumption choice:

$$
\begin{aligned}
& 0=\left(N_{t} C_{e, t}^{1-\chi^{-1}}+U_{t} C_{u, t}^{1-\chi^{-1}}\right)^{\frac{\chi^{-1}-\gamma}{1-\chi^{-1}}} N_{t} C_{e, t}^{-\chi^{-1}}+\Psi_{t} \phi_{t}-\Lambda_{t} N_{t}, \\
& 0=\left(N_{t} C_{e, t}^{1-\chi^{-1}}+U_{t} C_{u, t}^{1-\chi^{-1}}\right)^{\frac{\chi^{-1}-\gamma}{1-\chi^{-1}}} U_{t} C_{u, t}^{-\chi^{-1}}-\Psi_{t}-\Lambda_{t} U_{t} .
\end{aligned}
$$

The complementary slackness condition $\Psi_{t}\left(\phi_{t} C_{e, t}-C_{u, t}\right)=0$ implies that the sum of $C_{e, t}$ times (A.4) and $C_{u, t}$ times (A.5) is equal to

$$
\Lambda_{t}\left(N_{t} C_{e, t}+U_{t} C_{u, t}\right)=\left(N_{t} C_{e, t}^{1-\chi^{-1}}+U_{t} C_{u, t}^{1-\chi^{-1}}\right)^{\frac{1-\gamma}{1-\chi^{-1}}} .
$$


Substituting in equation (25) for aggregate consumption, we then obtain

$$
\Lambda_{t}=C_{t}^{-\gamma}\left(N_{t}\left(\frac{C_{e, t}}{C_{t}}\right)^{1-\chi^{-1}}+U_{t}\left(\frac{C_{u, t}}{C_{t}}\right)^{1-\chi^{-1}}\right)^{\frac{1-\gamma}{1-\chi^{-1}}}
$$

which corresponds to equation (29).

\section{A.2 Approximate bond risk premia}

The $\log$ of the $\operatorname{SDF}(32)$ is equal to $m_{t, t+n} \equiv \log M_{t, t+n}=n \log \beta-\gamma \Delta c_{t: t+n}+\Delta \log \zeta_{t: t+n}$. A log normal expression for the conditional entropy (36) yields

$L_{t}\left(M_{t, t+n}\right) \approx \frac{1}{2} \operatorname{Var}_{t}\left(m_{t, t+n}\right)=\frac{1}{2} \gamma^{2} \operatorname{Var}_{t}\left(\Delta c_{t: t+n}\right)+\frac{1}{2} \operatorname{Var}_{t}\left(\Delta \log \zeta_{t: t+n}\right)-\gamma \operatorname{Cov}_{t}\left(\Delta c_{t: t+n}, \Delta \log \zeta_{t: t+n}\right)$.

Plugging this expression into equation (37), we obtain

$$
h p x r_{t}^{H, T} \approx h p x r_{t}^{H, T, \Delta c}+h p x r_{t}^{H, T, \Delta \log \zeta}+h p x r_{t}^{H, T, C o v},
$$

where

$$
\begin{aligned}
& \operatorname{hpxr}_{t}^{H, T, \Delta c}=-\gamma^{2} \operatorname{Cov}_{t}\left(\Delta c_{t: t+H}, \Delta c_{t+H: t+T}\right) \\
& +\frac{1}{2} \gamma^{2} \mathbb{E}_{t}\left[\operatorname{Var}_{t+H}\left(\Delta c_{t+H: t+T}\right)-\operatorname{Var}_{t}\left(\Delta c_{t+H: t+T}\right)\right] \\
& \operatorname{hpxr}_{t}^{H, T, \Delta \log \zeta}=-\operatorname{Cov}_{t}\left(\Delta \log \zeta_{t: t+H}, \Delta \log \zeta_{t+H: t+T}\right) \\
& +\frac{1}{2} \mathbb{E}_{t}\left[\operatorname{Var}_{t+H}\left(\Delta \log \zeta_{t+H: t+T}\right)-\operatorname{Var}_{t}\left(\Delta \log \zeta_{t+H: t+T}\right)\right], \\
& h p x r_{t}^{H, T, C o v}=\gamma \operatorname{Cov}_{t}\left(\Delta c_{t: t+H}, \Delta \log \zeta_{t+H: t+T}\right)+\gamma \operatorname{Cov}_{t}\left(\Delta \log \zeta_{t: t+H}, \Delta c_{t+H: t+T}\right) \\
& -\gamma \mathbb{E}_{t}\left[\operatorname{Cov}_{t+H}\left(\Delta c_{t+H: t+T}, \Delta \log \zeta_{t+H: t+T}\right)-\operatorname{Cov}_{t}\left(\Delta c_{t+H: t+T}, \Delta \log \zeta_{t+H: t+T}\right)\right] .
\end{aligned}
$$

Finally, we arrive at expression (43) by ignoring the stochastic volatility terms in equation (A.8). That is, by ignoring the last term in each of the equations (A.9), (A.10), and (A.11).

\section{A.3 Computing nominal bond prices}

The inflation process (45) is of the form

$$
\Delta \pi_{t+1}=\mu_{\pi}\left(1-\rho_{\pi}\right)+\rho_{\pi} \Delta \pi_{t}+\xi_{\pi} \varepsilon_{\Delta c}\left(z_{t}, N_{t}, z_{t+1}, N_{t+1}\right)+\nu_{\pi} \varepsilon_{\pi, t}+\varepsilon_{\pi, t+1},
$$


with the aggregate consumption shock (46) being a function of $z_{t}, N_{t}, z_{t+1}$, and $N_{t+1}$. We begin by decomposing inflation into the sum of two orthogonal components:

$$
\begin{aligned}
& \Delta \pi_{t+1}=\Delta \pi_{t+1}^{(1)}+\Delta \pi_{t+1}^{(2)} \\
& \Delta \pi_{t+1}^{(1)}=\mu_{\pi}\left(1-\rho_{\pi}\right)+\rho_{\pi} \Delta \pi_{t}^{(1)}+\nu_{\pi} \varepsilon_{\pi, t}+\varepsilon_{\pi, t+1} \\
& \Delta \pi_{t+1}^{(2)}=\rho_{\pi} \Delta \pi_{t}^{(2)}+\xi_{\pi} \varepsilon_{\Delta c}\left(z_{t}, N_{t}, z_{t+1}, N_{t+1}\right) .
\end{aligned}
$$

The nominal bond price (44) then has functional form

$$
P_{t}^{(\$, n)}=P^{(\$, A, n)}\left(z_{t}, N_{t}\right) P^{(\$, B, n)}\left(\Delta \pi_{t}^{(1)}, \varepsilon_{\pi, t}\right) P^{(\$, C, n)}\left(\Delta \pi_{t}^{(2)}\right) .
$$

The first term on the right hand side of equation (A.16) can be computed recursively as follows:

$$
\begin{aligned}
P^{(\$, A, 0)}(z, N)=1, & \\
P^{(\$, A, n)}(z, N)=\mathbb{E} & {\left[M\left(z, N, z^{\prime}, N^{\prime}\right) \exp \left\{-\xi_{\pi}\left(1+\frac{\rho_{\pi}\left(1-\rho_{\pi}^{n-1}\right)}{1-\rho_{\pi}}\right) \varepsilon_{\Delta c}\left(z, N, z^{\prime}, N^{\prime}\right)\right\}\right.} \\
& \left.\times P^{(\$, A, n-1)}\left(z^{\prime}, N^{\prime}\right) \mid z, N\right] .
\end{aligned}
$$

Next, the second term on the right hand side of equation (A.16) is given by

$$
P^{(\$, B, n)}\left(\Delta \pi^{(1)}, \varepsilon_{\pi}\right)=\exp \left(-a^{(\$, B, n)}-b^{(\$, B, n)} \Delta \pi^{(1)}-c^{(\$, B, n)} \varepsilon_{\pi}\right),
$$

where the coefficients can be computed recursively:

$$
\begin{aligned}
a^{(\$, B, n)} & =a^{(\$, B, n-1)}+\mu_{\pi}\left(1-\rho_{\pi}\right)\left(1+b^{(\$, B, n-1)}\right)-\frac{\sigma_{\pi}^{2}}{2}\left(1+b^{(\$, B, n-1)}+c^{(\$, B, n-1)}\right)^{2}( \\
b^{(\$, B, n)} & =\rho_{\pi}\left(1+b^{(\$, B, n-1)}\right) \\
c^{(\$, B, n)} & =\nu_{\pi}\left(1+b^{(\$, B, n-1)}\right)
\end{aligned}
$$

starting from the initial condition

$$
a^{(\$, B, 0)}=b^{(\$, B, 0)}=c^{(\$, B, 0)}=0 .
$$

Finally, the third term on the right hand side of equation (A.16) is given by

$$
P^{(\$, C, n)}\left(\Delta \pi^{(2)}\right)=\exp \left(-\frac{\rho_{\pi}\left(1-\rho_{\pi}^{n}\right)}{1-\rho_{\pi}} \Delta \pi^{(2)}\right) .
$$




\section{B Empirical Appendix}

We use data from the sources described below.

Nominal bond returns. We use the Fama-Bliss Discount Bonds monthly series from the Center for Research in Security Prices.

Aggregate consumption. First, we use the quarterly real personal consumption expenditures per capita (A794RX0Q048SBEA) series, retrieved from Federal Reserve Economic Data (FRED), to compute the data moments for aggregate consumption growth reported in Table 2. Second, we construct a monthly series for real aggregate consumption by using the Personal Consumption Expenditures: Chain-type Price Index (PCEPI) series to deflate the Personal Consumption Expenditures (PCE) series. The resulting monthly series is used to construct the consumption growth innovations (46).

Inflation. We measure inflation based on growth in the Consumer Price Index (CPIAUCSL) series, which we downloaded from FRED.

Monetary policy. We measure monetary policy using the effective Federal Funds Rate (FEDFUNDS) series, which we downloaded from FRED.

Bond supply. We measure nominal bond supply using the maturity weighted debt to GDP series from the data appendix of Greenwood and Vayanos (2014).

Labor market tightness. Tightness is the ratio of (1) the composite Help Wanted Index from Barnichon (2010), downloaded from Regis Barnichon's website https://sites.google.com/site/ regisbarnichon/data; and (2) the seasonally adjusted civilian unemployment rate (UNRATE) series, downloaded from FRED.

Job-finding and separation rates. We construct job-finding and separation rates following the procedure in Elsby, Michaels, and Solon (2009). This procedure makes use of the following series from FRED: civilian labor force size (CLF16OV), unemployment level (UNEMPLOY), and number of civilians unemployed for less than 5 weeks (UEMPLT5). 


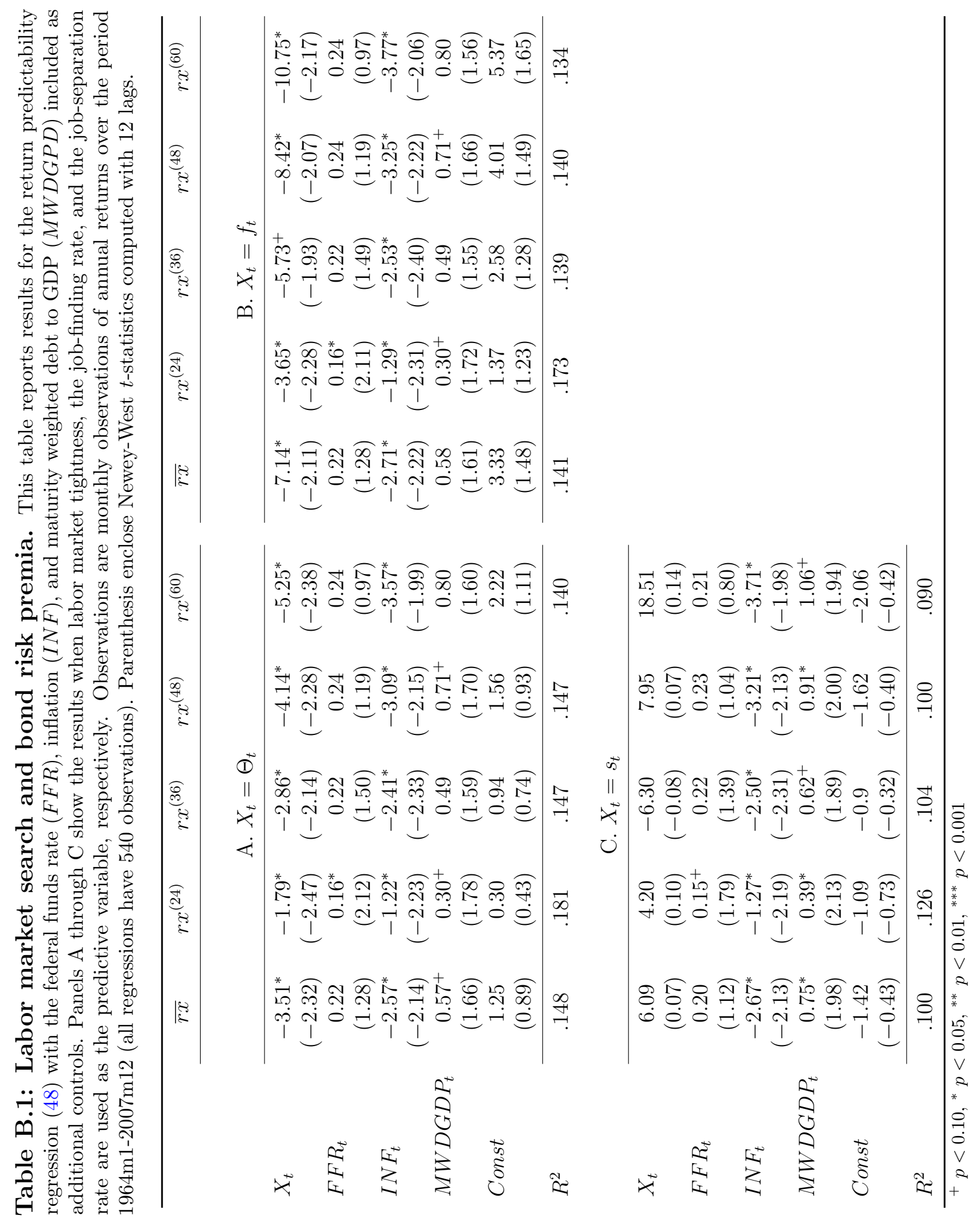




\section{References}

Abel, A. B., 1999, "Risk premia and term premia in general equilibrium," Journal of Monetary Economics, 43, 3-33.

Ai, H., and A. Bhandari, 2018, "Asset Pricing with Endogenously Uninsurable Tail Risk," NBER Working Paper No. 24972.

Andolfatto, D., 1996, "Business Cycles and Labor-Market Search," American Economic Review, 86, 112-32.

Backus, D., N. Boyarchenko, and M. Chernov, 2018, "Term structures of asset prices and returns," Journal of Financial Economics, 129, 1 - 23.

Backus, D., M. Chernov, and S. Zin, 2014, "Sources of Entropy in Representative Agent Models," Journal of Finance, 69, 51-99.

Backus, D., A. Gregory, and S. Zin, 1989, "Risk premiums in the term structure: Evidence from artificial economies," Journal of Monetary Economics, 24, 371-399.

Bansal, R., and I. Shaliastovich, 2013, "A Long-Run Risks Explanation of Predictability Puzzles in Bond and Currency Markets," Review of Financial Studies, 26, 1-33.

Barnichon, R., 2010, "Building a composite Help-Wanted Index," Economics Letters, 109, $175-178$.

Barton, D. E., F. N. David, and E. Fix, 1962, "Persistence in a chain of multiple events," Biometrika, 49.

Belo, F., A. Donangelo, X. Lin, and D. Luo, 2017, "Labor Hiring and Discount Rates," Working paper.

Belo, F., X. Lin, and S. Bazdresch, 2014, "Labor Hiring, Investment, and Stock Return Predictability in the Cross Section," Journal of Political Economy, 122, 129-177.

Bianchi, D., M. Büchner, and A. Tamoni, 2019, "Bond Risk Premia with Machine Learning," Review of Financial Studies, forthcoming.

Breeden, D. T., 1979, "An intertemporal asset pricing model with stochastic consumption and investment opportunities," Journal of Financial Economics, 7, 265 - 296.

Breeden, D. T., R. H. Litzenberger, and T. Jia, 2015, "Consumption-Based Asset Pricing, Part 1: Classic Theory and Tests, Measurement Issues, and Limited Participation," Annual Review of Financial Economics, 7, 35-83. 
Bretscher, L., A. Hsu, and A. Tamoni, forthcoming, "Fiscal Policy Driven Bond Risk Premia," Journal of Financial Economics.

Campbell, J., and R. Shiller, 1991, "Yield Spreads and Interest Rate Movements: A Bird's Eye View," Review of Economic Studies, 58, 495-514.

Chen, A. Y., 2017, "External Habit in a Production Economy: A Model of Asset Prices and Consumption Volatility Risk," Review of Financial Studies, 30, 2890-2932.

Cochrane, J. H., 1988, "Production Based Asset Pricing," Working Paper 2776, National Bureau of Economic Research.

Cochrane, J. H., and M. Piazzesi, 2005, "Bond Risk Premia," American Economic Review, $95,138-160$.

Constantinides, G. M., and D. Duffie, 1996, "Asset Pricing with Heterogeneous Consumers," Journal of Political Economy, 104, 219-240.

Constantinides, G. M., and A. Ghosh, 2017, "Asset Pricing with Countercyclical Household Consumption Risk," Journal of Finance, 72, 415-460.

den Haan, W., G. Ramey, and J. Watson, 2000, "Job Destruction and Propagation of Shocks," American Economic Review, 90, 482-498.

den Haan, W. J., 1995, "The term structure of interest rates in real and monetary economies," Journal of Economic Dynamics and Control, 19, 909 - 940.

Diamond, P. A., 1982, "Wage Determination and Efficiency in Search Equilibrium," Review of Economic Studies, 49, 217-227.

Donaldson, J. B., T. Johnsen, and R. Mehra, 1990, "On the Term Structure of Interest Rates," Journal of Economic Dynamics and Control, pp. 571-596.

Donangelo, A., 2014, "Labor Mobility: Implications for Asset Pricing," Journal of Finance, $68,1321-1346$.

Duffee, G. R., 2013, "Bond Pricing and the Macroeconomy," , vol. 2 of Handbook of the Economics of Finance . chap. 13, pp. 907 - 967, Elsevier.

Dybvig, P., and S. Ross, 1987, "Arbitrage," in John Eatwell, Murray Milgate, and Peter Newman (ed.), The New Palgrave Dictionary of Economics, Macmillan and Stockton, first edn. 
Dybvig, P., and S. Ross, 2003, "Arbitrage, state prices and portfolio theory," in George Constantinides, Milton Harris, and Rene Stulz (ed.), Handbook of Economics and Finance, Elsevier.

Ehling, P., M. Gallmeyer, C. Heyerdahl-Larsen, and P. Illeditsch, 2018, "Disagreement about inflation and the yield curve," Journal of Financial Economics, 127, 459 - 484.

Elsby, M. W. L., R. Michaels, and G. Solon, 2009, "The Ins and Outs of Cyclical Unemployment," American Economic Journal: Macroeconomics, 1, 84-110.

Fama, E. F., and R. R. Bliss, 1987, "The Information in Long-Maturity Forward Rates," American Economic Review, 77, 680-692.

Favilukis, J., and X. Lin, 2015, "Wage rigidity: A quantitative solution to several asset pricing puzzles," The Review of Financial Studies, 29, 148-192.

Favilukis, J., X. Lin, and X. Zhao, 2019, "The Elephant in the Room: the Impact of Labor Obligations on Credit Risk," American Economic Review, forthcoming.

Gallmeyer, M. F., B. Hollifield, F. J. Palomino, and S. E. Zin, 2007, "Arbitrage-free bond pricing with dynamic macroeconomic models," Review, Federal Reserve Bank of St. Louis, pp. 305-326.

Greenwood, R., and D. Vayanos, 2014, "Bond Supply and Excess Bond Returns," Review of Financial Studies, 27.

Guvenen, F., S. Ozkan, and J. Song, 2014, "The Nature of Countercyclical Income Risk," Journal of Political Economy, 122, 621-660.

Haddad, V., and D. Sraer, 2020, "The Banking View of Bond Risk Premia," Journal of Finance, 75, 2465-2502.

Hagedorn, M., and I. Manovskii, 2008, "The Cyclical Behavior of Equilibrium Unemployment and Vacancies Revisited," American Economic Review, 98, 1692-1706.

Hall, R. E., and S. Schulhofer-Wohl, 2017, "The Pervasive Importance of Tightness in Labor-Market Volatility," Working paper, Stanford University.

Haubrich, J., G. Pennacchi, and P. Ritchken, 2012, "Inflation Expectations, Real Rates, and Risk Premia: Evidence from Inflation Swaps," The Review of Financial Studies, 25, $1588-1629$.

Hong, H., D. Sraer, and J. Yu, 2016, "Inflation Bets on the Long Bond," Review of Financial Studies, 30, 900-947. 
Hsu, A. C., E. X. Li, and F. Palomino, 2019, "Real and Nominal Equilibrium Yield Curves: Wage Rigidities and Permanent Shocks," Management Science, forthcoming.

Huang, J.-Z., and Z. Shi, 2016, "Understanding Term Premia on Real Bonds," Working paper.

Huang, J.-Z., and Z. Shi, 2019, "Determinants of Bond Risk Premia: A Machine-LearningBased Resolution of the Spanning Controversy," Working paper.

Jermann, U., 2013, "A production-based model for the term structure," Journal of Financial Economics, 109, 293-306.

Joslin, S., M. Priebsch, and K. J. Singleton, 2014, "Risk Premiums in Dynamic Term Structure Models with Unspanned Macro Risks," Journal of Finance, 69, 1197-1233.

Kogan, L., D. Papanikolaou, and N. Stoffman, 2020, "Left Behind: Creative Destruction, Inequality, and the Stock Market," Journal of Political Economy, 128, 855-906.

Kuehn, L.-A., M. Simutin, and J. J. Wang, 2017, "A Labor Capital Asset Pricing Model," The Journal of Finance, 72, 2131-2178.

Kung, H., 2015, "Macroeconomic linkages between monetary policy and the term structure of interest rates," Journal of Financial Economics, 115, $42-57$.

Le, A., and K. J. Singleton, 2010, "An equilibrium term structure model with recursive preferences," American Economic Review, 100, 557-561.

Liu, Y., 2018, "Labor-Based Asset Pricing," Working paper.

Ludvigson, S. C., and S. Ng, 2009, "Macro Factors in Bond Risk Premia," Review of Financial Studies, 22, 5027-5067.

Merz, M., 1995, "Search in the labor market and the real business cycle," Journal of Monetary Economics, 36, 269-300.

Mortensen, D. T., and C. A. Pissarides, 1994, "Job Creation and Destruction in the Theory of Unemployment," Review of Economic Studies, 61, 397-415.

Petrosky-Nadeau, N., L. Zhang, and L.-A. Kuehn, 2018, "Endogenous Disasters," American Economic Review, 108, 2212-2245.

Pflueger, C., and L. M. Viceira, 2011, "Inflation-Indexed Bonds and the Expectations Hypothesis," Annual Review of Financial Economics, 3, 139-158. 
Pflueger, C. E., and L. M. Viceira, 2016, Return Predictability in the Treasury Market: Real Rates, Inflation, and Liquidity . chap. 10, pp. 191-209, John Wiley and Sons, Ltd.

Piazzesi, M., and M. Schneider, 2007, "Equilibrium Yield Curves," in Daron Acemoglu, Kenneth Rogoff, and Michael Woodford (ed.), NBER Macroeconomics Annual 2006, vol. 21, . pp. 389-472, MIT Press, Cambridge, MA.

Pissarides, C. A., 1985, "Short-Run Equilibrium Dynamics of Unemployment, Vacancies, and Real Wages," American Economic Review, 75, 676-690.

Rudebusch, G. D., and E. T. Swanson, 2008, "Examining the bond premium puzzle with a DSGE model," Journal of Monetary Economics, 55, S111 - S126.

Rudebusch, G. D., and E. T. Swanson, 2012, "The Bond Premium in a DSGE Model with Long-Run Real and Nominal Risks," American Economic Journal: Macroeconomics, 4, $105-43$.

Schmidt, L., 2016, "Climbing and Falling Off the Ladder: Asset Pricing Implications of Labor Market Event Risk," Working paper.

Schneider, A., 2019, "Risk Sharing and the Term Structure of Interest Rates," Working paper.

Shimer, R., 2005, "The Cyclical Behavior of Equilibrium Unemployment and Vacancies," American Economic Review, 95, 25-49.

Singleton, K. J., 2006, Empirical Dynamic Asset Pricing: Model Specification and Econometric Assessment, Princeton University Press.

van Binsbergen, J. H., J. Fernandez-Villaverde, R. S. Koijen, and J. Rubio-Ramirez, 2012, "The term structure of interest rates in a DSGE model with recursive preferences," Journal of Monetary Economics, 59, $634-648$.

Wachter, J., 2006, "A consumption-based model of the term structure of interest rates," Journal of Financial Economics, 79, 365-399. 